NOTICE: this is the author's version of a work that was accepted for publication in Advances in Water Resources. Changes resulting from the publishing process, such as peer review, editing, corrections, structural formatting, and other quality control mechanisms may not be reflected in this document. Changes may have been made to this work since it was submitted for publication. A definitive version was subsequently published in Advances in Water Resources, Vol. 54 (2013). DOI: 10.1016/j.advwatres.2013.01.001 
Page 1 of 47

\section{The influence of Low Frequency Sea Surface Temperature modes on Delineated Decadal Rainfall zones in Eastern Africa region}

3

4 


\begin{abstract}
1 Abstract
2 Influence of low frequency global Sea Surface Temperatures (SSTs) modes on decadal 3 rainfall over Eastern Africa region is investigated. Fore-knowledge of rainfall distribution at 4 decadal time scale in specific zones is critical for planning purposes. Both rainfall and SST 5 data that covers a period of 1950 to 2008 were subjected to a 'low-pass filter' in order to 6 suppress the high frequency oscillations. VARIMAX-Rotated Principal Component Analysis 7 (RPCA) was employed to delineate the region into decadal rainfall zones while Singular 8 Value Decomposition (SVD) techniques was used to examine potential linkages of these 9 zones to various areas of the tropical global oceans. Ten-year distinct decadal signals, 10 significant at 95\% confidence level, are dominant when observed in-situ rainfall time series 11 are subjected to spectral analysis. The presence of variability at El Niño Southern 12 Oscillation (ENSO)-related timescales, combined with influences in the 10-12 year and 161320 year bands were also prevalent. Nine and seven homogeneous decadal rainfall zones for 14 long rainfall season i.e. March-May (MAM) and the short rainfall season i.e. October15 December (OND), respectively, are delineated. The third season of June - August (JJA), 16 which is mainly experienced in western and Coastal sub-regions had eight homogenous 17 zones delineated. The forcing of decadal rainfall in the region is linked the equatorial 18 central Pacific Ocean, the tropical and South Atlantic Oceans, and the Southwest Indian 19 Ocean. The high variability of these modes highlighted the significant roles of all the global 20 oceans in forcing decadal rainfall variability over the region.
\end{abstract}

Keywords: Decadal Rainfall Variability, Sea Surface Temperatures, Singular Value Decomposition

Corresponding author contact: P. Omondi, IGAD Climate Prediction and Applications Centre, 


\section{Introduction}

Spatial and temporal variability of rainfall offers considerable challenges for assessing and understanding climate change and variability over Eastern Africa region. The region is already witnessing dire consequences of erratic climatic conditions that are likely to be associated with regional climate change (IPCC 2007). The recurrences of floods and droughts have been associated with many socio-economic miseries. This is a region with serious food insecurity and resources-based conflicts. IPCC (2007) report provided clear evidences of climate change in the region with increased risks of climate extremes. Unfortunately, the economies and livelihoods of the majority of the countries in the region still rely on rain dependent systems. Serious food insecurity, famines, and poverty among other miseries, are prevalent in the region. The rainfall pattern over the region is highly variable both in space and time because of the complexity of regional climates and the influence of regional geographic features, such as semi-arid lands, land cover variations, mountain chains, large lakes, land-sea contrasts, and the sea surface temperature (SST) changes of the surrounding Indian Ocean. Such diversity influences the distribution and statistics of rainfall extremes at all scales. This in turn may have a much greater impact on natural systems and human activities than mean precipitation (Parry et al., 2007).

Atmospheric motions are dominated by the gradients in temperature and the associated pressure gradients (Barry and Chorley 1968; Nyakwada 2009). The use of SST gradients can improve the representation of the driving forces of the general circulation. The SST gradients influence wind currents and the associated moisture transport (Lindzen and Nigam 1987). Some of the SST gradients that have been documented to influence climate of the region and beyond include the Zonal SST gradients in the Indian Ocean associated with the Indian Ocean Dipole (IOD) (Saji et al 1999, Webster et al. 1999, Yu and Riennecker 2000, Clark et al 2003, Behera et al 2005, Owiti 2005, Singhrattna et al 2005); the zonal SST gradient in the Pacific (Bjerkness 1969; Nyakwada 2009) and the zonal and meridional SST gradients in the Atlantic Ocean (Moura and Shukla 1981; Nobre and Shukla 1996; Wang 2002). The meridional and zonal SST gradients are linked through teleconnections with large-scale atmospheric circulation such as the Walker and Hadley cells (Wang 2002). The zonal and meridional SST gradients have a strong signature on the climate of the tropical areas (Lindzen and Nigam 1987; Ward 1998). In the tropics the zonal gradients are generally smaller than the meridional gradients but are more important in forcing low level tropical circulation and convergence than the meridional gradients (Lindzen and Nigam 1987).

There is particular interest in the coming decade, which represents a key planning horizon for infrastructure upgrades, insurance, energy policy, and business development. Societal needs for climate information on decadal time scales is continuing to grow in terms of its potential value and relevance as a driver in sector decision making. However, such information is currently lacking in the region. Predictions and observationally-based analyses for decadal climate variability and change are therefore needed. A large timescale gap, especially the one that goes from one year to about 20 years, exists in climate predictions (Reason et al., 2006; Smith et al., 2007; IPCC 2007). Long term scale climate predictions over East African region has not been done with enough precision to 
adequately carry out assessment of impacts of climate anomalies at the sub-regional level. For interventions and planning purposes, climate information is required on average over 5 to 10 years. Only recently has this received attention of the scientific community despite the relevance of this timescale to many societal and developmental applications (see e.g. Smith et al., 2007; Keenlyside et al., 2008; Pohlmann et al., 2009). These scientific and technical shortcomings in turn act as a major hurdle that limits the ability to design and justify investment decisions for the development and design of appropriate adaptation strategies.

Knowledge on decadal climate variability is popularly emerging as a new direction in climate science (CLIVAR Vacs, 2007; Meehl and Hibbard, 2007; Seager et al., 2007; Knutson and Tuleya, 2004; Meehl et al., 2009), especially in light of increased demand for climate and climate change information. Numerous assessments of climate information user needs have identified this timescale as being important to infrastructure planners, water resource managers, and many others (Meehl et al., 2009; Lee et al., 2006; Keenlyside., 2008). Decadal prediction lies between seasonal/interannual forecasting and longer term climate change projections, and further focuses on time-evolving regional climate conditions over the next 10-30 years. Perhaps the most striking finding is the linkage of decadal drought frequency in the Sahel to SST (Nicholson 2000a; L'H^ote et al., 2002; Zhang and Delworth, 2006). Other droughts on decadal-timescale, such as the "dust-bowl" in the Southern United States of America (USA) in the 1930s have been linked to variations in SST (Worster, 1979; Woodhouse and Overpeck, 1998; Bark, 1978). Nicholson (2000b) showed rainfall time series for 1901-1994 of three African regions displaying decadal rainfall variations. In South Africa, and some neighboring areas, an austral summer rainfall signal at near bidecadal scales has been known for some time (Tyson and Preston-Whyte, 2000). In the Pacific/Indian Ocean basins, there are strong signals of decadal variability associated with the Pacific Decadal Oscillation (PDO) with statistical links to the climate of the surrounding regions. For example, during the 20th century, El Niño- like phases of the PDO coincided with decades in which ENSOs impact on Australia was weak, whereas La Niña- like phases of the PDO coincided with decades in which ENSOs impact on Australia was strong (Power et al, 1999).

Over East Africa region, there is substantial evidence for decadal climate variability in the observed climate system (Nicholson 2000b; Schreck and Semazzi, 2004; Bowden et al., 2004, Muthama et al., 2008; Omondi et al 2009; Omondi et al., 2012a,b). Decadal rainfall signals in East Africa have been linked to the Pacific Decadal Oscillation (PDO) (CLIVAR VACS 2007). Several parts of the region experience strong decadal signal during the short rains of OND season (Schreck and Semazzi, 2004; Bowden et al., 2004; Omondi et al 2009; CLIVAR VACS, 2007). Recently, Omondi et al., 2009 provided some evidence of decadal variability in the interannual patterns of East Africa rainfall. They showed that some teleconnections were evident between the observed decadal rainfall and SST variability patterns over parts of the global oceans. They further found correlations between the rainfall and SSTs but no attempt was made in linking regional homogenous zones to specific regions of global SSTs. Relatively less attention has been directed at the influence of low frequency SST signals in forcing decadal rainfall in different sub-regions of East

46 Africa. 
The focus of the present study therefore, is to extend the work of Omondi et al., 2009 by delineating the sub-regions of Eastern Africa based on decadal rainfall variability and investigate how these sub-regions are coupled to low frequency SST signals. Unlike in Omondi et al., 2009 where a simple correlation analysis was employed, this study applied the more sophisticated Singular Value Decomposition (SVD) technique in attempt to link decadal rainfall to various global basins SSTs. The advantage of adding this step to the analysis is twofold: 1) It improves the performance of statistical methods with removing highly correlated observation in each region, which might add unrealistic weights to the zones with more stations and disturb the leading components towards the maximum variability of those zones (see e.g., Basalirwa, 1995 ). 2) It also groups together stations with common decadal rainfall characteristics into homogeneous zones, which considerably improves the interpretation of the results. Once the homogeneous regions are identified, again we investigate both spatial and temporal coupling over a longer period of time compared the previous work where only temporal variability was considered and over a relatively shorter period of time.

This study is organized as follows: A brief discussion of the types of data used in the study and methods of analysis are present in section 2. The key results are discussed in section 3, whereas summary and conclusions are provided in section 4 .

\section{Data and methods}

\subsection{Observed climate data}

The rain gauge observations network over East Africa is quite sparse. Furthermore, the available data are also riddled with numerous gaps in both space and time. These limitations in the quantity and quality of in-situ observations impose substantial constraints on diagnostic studies of the regional climate (rainfall) variability. The observed rainfall data used in this study consist of monthly rainfall data (1920-2008) obtained from the Kenya Meteorological Department (KMD), Tanzania Meteorological Agency (TMA) and Uganda Meteorological Department (UMD). The in-situ rainfall stations used in this study are the representative stations for 37 climatological zones used by the three countries in day-to-day operations (ICPAC 1999). These were earlier computed using PCA analysis and have been used by many authors in the region. A total of 37, unevenly distributed, gauge stations over East Africa were available for the analysis.

The SST data used in this study is from the National Center for Environmental Prediction/Climate Prediction Center (NCEP/CPC) for the period 1950-2008 which is distributed under the National Oceanic and Atmospheric Administration (NOAA) / Climate Diagnostic Center (CDC) Optimum Interpolation (OI) SST Version 2 (OISSTv.2). The data are on $1.0^{0} \times 1.0^{\circ}$ grid point resolution and is often known as optimal interpolation (OI) SST in literature following Reynolds and Smith (1994). The data set is a blend of insitu and satellite SSTs, but also includes those simulated by sea-ice cover (Reynolds et al., 2002; Smith and Reynold, 2002). The data adjustment for biases was done using the method described by Reynolds (1988) and Reynolds and Marsico (1993). Details of this methodology can be found in Reynolds and Smith (1994). All SST observed data within 
$30^{\circ} \mathrm{S}-30^{\circ} \mathrm{N}$ are discarded if the value is less than $-2^{\circ} \mathrm{C}$ or greater than $35^{\circ} \mathrm{C}$ or if the SST anomaly lies outside \pm 3.5 times the climatological standard deviation.

SSTs have long memory and therefore have wide usage in most climate prediction models (Mutemi, 2003; Owiti, 2005; Smith et al., 2007; Smith et al., 2008; Nyakwada, 2009). Several efforts have been made to improve the quality of SST records due to their value in climate prediction (Smith and Reynolds, 2004; Smith et al., 2008). Kanamitsu et al., (2002); Smith and Reynolds, $(2002,2004)$ and Smith et al., (2008) among other authors, have discussed the details of these data. It is important to note that SST data to the south of $30^{\circ} \mathrm{S}$ may not be of good quality as indicated in the study of Weare (1977) and hence the present study was restricted between $30^{\circ} \mathrm{S}$ and $30^{\circ} \mathrm{N}$ of the tropical global Oceans.

We briefly highlight the methodology employed in analysis for the study in the section that follows. However, in establishing the relationship between rainfall and temperature, a common window for both data sets is set as 1950-2008. Both data sets were low-pass filtered using a nine-term binomial coefficient filter or ten years moving average to remove all fluctuations equal to and less than 10 years. It is also noteworthy that when any time series is subjected to nine point Gaussian probability curve, four years of data are truncated from both ends of the series. The graphical presentations these series include the plotting of the bar charts anomalies obtained when long-term mean decadal rainfall is subtracted from the filtered record and the ensuing series detrended.

\subsection{Spectral Analysis Method}

Spectral analysis is a technique for examining the hidden periodicities (cycles or oscillations) of any time series at certain frequencies. The objective of spectral analysis is to determine the actual distribution of frequencies in a signal. Spectral analysis has been used by many authors to examine cyclic variations (e.g. Bloomfield 1976; Wilks 1995, 2006; Muhati et al., 2007).

In statistical signal processing, the spectral density, power spectral density (PSD), or energy spectral density (ESD), is a positive real function of a frequency variable associated with a stationary stochastic process, or a deterministic function of time. The power spectral density of a signal can be estimated by a periodogram. A spectral plot refers to a smoothed version of the periodogram performed to reduce the effect of measurement noise. Raw periodogram is not a good spectral estimate because of spectral bias and the fact that the variance at a given frequency does not decrease as the number of samples used in the computation increases. The variance problem can be reduced by smoothing the periodogram. Various techniques to reduce spectral bias and variance are the subject of spectral estimation. The purpose of estimating the spectral density is to detect any periodicities in the data, by observing peaks at the frequencies corresponding to these periodicities.

40

The spectral analysis density function $h(w)$ can be expressed as a Fourier transform of

42 autocovariance function $R(r)$. Thus

$43 \quad h(w)=\frac{1}{2 \pi} \sum_{r=-\infty}^{\infty} e^{-i w r} R(r)-p £ w £ p$ 
1 Where $\omega=2 \pi f$ is the angular frequency and $f$ is the frequency and $i=\sqrt{-1}$. In the normalized power spectrum $\mid(\omega)$, the autocovariance is replaced by autocorrelation, and

3 takes form

$4 \quad \mid(\omega)=\frac{1}{2 \pi} \sum_{r=\infty}^{\infty} e^{-i \omega r} \rho(r)$

In order to obtain consistent estimates of $\mid(\omega)$, smoothing functions $\lambda(r)$ are used. The smoothed spectral density function, $\left.\right|^{1}(\omega)$ may be expressed as $\left.\right|^{1}(\omega) £|(\mathrm{r})|(\omega)$. Where $\lambda(r)$ the smoothing is weights or lag windows (Muhati et al., 2007). Examples of lag windows that are used to smooth the power spectrum are: Truncated Periodogram, Bartlett, Daniel, Tukey Humming, Tukey Hunning, Parsen and Barklett-Priestley windows (Bloomfield 1976, Wilks 1995). The most commonly used windows are the Parsen and Tukey windows (Jenkins and watts, 1968).

Significance testing of spectral estimates is performed using methods outlined in Minja (1984) and Koopmans (1995). The upper and lower bounds of a confidence interval around each spectral estimate were computed using $\chi^{2}$ distribution. In order to set up confidence interval, it is necessary to determine the equivalent degrees of freedom (edf) for the new (smoothed) spectral estimates. Prior to smoothing, each periodogram intensity estimates has $2 d f$; after smoothing, the estimated new edf will vary depending upon the width and shape of the smoothing window. For the Daniell window, the edf is easily determined: it is just $2 \mathrm{M}$, where $\mathrm{M}$ is the total width of the window (the number of frequencies that are included in the weighted average). Details of the computations of weights and of the edf for other windows can be obtained from Gottman (1981) and 23 Koopmans (1995).

24 For a 98\% confidence interval $(C L)$, the critical values of $\chi^{2}$ (for this edf) that cut off the 25 bottom and top $1 \%$ are obtained by table lookup in the $\chi^{2}$ distribution. In the formula that 26 follows, these are denoted $\chi_{.01}^{2}$ for the bottom $1 \%$ cutoff and $\chi_{.99}^{2}$ for the top $1 \%$ cutoff 27 critical values of $\chi^{2}$. The spectral estimate for which the $C L$ is set up is denoted by $s\left(f_{i}\right)$, 28 where $f_{i}$ is the specific frequency and $s\left(f_{i}\right)$ is the estimated power at that frequency. 29 Thus the upper and lower bounds of a 98\% CL for $s(f)$ are given by as:

30 Lower bound of $C L=[e d f . s(f)] / \chi_{.99}^{2}$

31 Upper bound of $C L=\left[e d f . s\left(f_{i}\right)\right] / \chi_{.01}^{2}$

32 The width of the $C L$ varies as a function of the size of $s\left(f_{i}\right)$, and so if $s\left(f_{i}\right)$ is plotted on a 33 linear scale a separate $C L$ must be set up for each spectral estimate. 
Given that the null hypothesis ("white noise") implies a uniform distribution of power across frequencies, a line can drawn on the graph of the power spectrum that corresponds to this mean level of power (i.e., the mean of all the spectral estimates). To test whether a specific spectral estimate is statistically significant, one can then examine its $C L$ to see whether it overlaps this mean. Should it not overlap the mean of the spectrum, then this spectral estimate might be judged to be significantly higher than expected by chance. However, this approach to significance testing raises a problem of inflated Type I error (Bloomfield, 1976). If the analyst specifies a very limited number of frequencies a priori and tests whether the power at these frequencies significantly exceeds the mean level of power (that would be expected if the series were white noise), this significance testing procedure may have acceptably low risk of Type I. When the largest peak in a spectrum is tested in this manner post hoc, then the actual risk of Type I error will be higher than the normal $\alpha$ level.

Because the CL approach to significance testing does not control for the inflated risk of Type I error that arises when many spectral estimates are tested post hoc for significance, the one may wish to take a more conservative approach may instead apply the Fisher test to the periodogram as a means of assessing significance of periodicity. Alternatively, one may wish to set up a CL for $99 \%$ or $99.9 \%$ to reduce the risk of Type I error.

In this study, we employ spectral analysis technique to detect periodic or quasi-periodic fluctuations and if the smoothed rainfall record is dominated with ten years cycle.

\subsection{VARIMAX-Rotated Principal Component Analysis (RPCA)}

Seasonal rainfall patterns over East Africa are known to be highly variable due to the existence of complex topography and large inland water bodies (Ogallo, 1988; Indeje, 2000; Mutemi, 2003; Nyakwada, 2009, Anyah and Qiu 2012). To prepare a spatially largest possible area for coherent rainfall having similar characteristics and associations with regional/global circulation parameters, homogenous zones are delineated. Spatial averages are more representatives of the large-scale conditions than are data for individual stations (Nicholson 1986). The use of normalized regionally averaged series reduce two problems inherent in the analysis of rainfall in the sub-humid, tropical areas namely; the highly diverse means and variabilities and the randomness of the convective process reflected in individual station totals (Ogallo, 1988; Indeje, 2000). Reduction of regional data and delineation of homogeneous climate zones is critical in studying mechanisms associated with these modes of variability. Regionalization and averaging of rainfall over large but homogeneous regions have the advantages of reducing meteorological noise in the data as well as minimizing the number of variables which describe the regional climate variability (Ogallo, 1988; Indeje, 2000; Mutemi, 2003; Nyakwada, 2009). To effectively provide a better understanding of the physical processes responsible for decadal climate variability over the region, we employ VARIMAX-Rotated PCA (RPCA) technique (Indeje, 2000; Mutemi, 2003; Nyakwada, 2009) to isolate dominant modes of the decadal rainfall variability and cluster analysis on the rainfall stations network to group them into homogeneous decadal rainfall zones. The delineation of homogeneous zones is followed by identifying the stations with the largest correlation with the Principal Component (PC) time series associated with the first eigenvector of the decadal rainfall anomaly (Basalirwa 1991, Indeje et al., 2000). 
In this study, the VARIMAX rotated version of PCA was applied to define dominant modes of variability of the low passed rainfall and SST series. The VARIMAX rotation is selected to improve the physical interpretation of the PCA modes and to derive more localized components (Richman 1986). We therefore employ PCA concept in this study to establish the dominant modes in both decadal rainfall and SST data. The spatial patterns of the dominant modes observed in the SST fields are thereafter used in the selection of SSTs modes from the major global basins for the model development. The use of PCA, however, requires the identification of the number of factors, which must be included in the solutions. A detailed discussion on selection rules are documented in e.g., (Kaiser 1958, Kaiser 1959, Cattel 1966, Wilks 2006).

\subsection{Singular Value Decomposition (SVD)}

The purpose of Singular Value Decomposition (SVD) is to reduce a dataset containing a large number of values to a dataset containing significantly fewer values, but which still contains a large fraction of the variability present in the original data (von Storch and Navarra, 1995). Often in the rainfall and SST data will exhibit large spatial correlations. SVD analysis results in a more compact representation of these correlations, especially with multivariate datasets and can provide insight into spatial and temporal variations exhibited in the data being analyzed.

In this study, SVD method aims to relate the two fields by decomposing their joint covariance matrix into singular values and two sets of paired-orthogonal vectors-one for each field. The covariance between the expansion coefficients of the leading pattern in each field is maximized. The singular values give the magnitude of the Squared Covariance Fraction (SCF) as accounted for by the various singular values (Bretherton et al. 1992; Wallace et al. 1992). Thus, SVD is a better approach compared to simple correlation analysis between different components of climate systems.

The SVD method is used in this study to further examine the detailed patterns of the dominant modes of decadal variations in rainfall and their coupling to the global SST changes. Detailed descriptions of SVD analysis can be found, e.g., in Bretherton et al., (1992) and von Storch and Navarra (1995). Exploiting the spatial coherence of climate signals in data series with low signal to noise ratios facilitates their identification (Mann and Park, 1996) while preserving spatial information and allowing the isolation of signals that might largely cancel in coarse spatial averaging (e.g., signals which largely involve dipole and quadrupole patterns). The usage of the SVD method in this study, therefore, is similar to canonical correlation analysis (CCA) where two sets of orthogonal time series are produced, along with their corresponding spatial patterns. CCA aims to maximize correlation between variables, while SVD aims to maximize covariance between variables. The difference between CCA and SVD is that CCA identifies spatial patterns by maximizing the temporal correlation between two data fields, whereas SVD maximizes the temporal covariance between two data fields. Barnston and Smith (1996) provide an in-depth analysis of CCA and its relation to SVD.

43

It should be noted that prior to SVD analysis, the series were subjected to a 'low- pass filter' in order to suppress the high frequency oscillations. The weights used were nine point 
Gaussian probability curve $(0.01,0.05,0.12,0.20,0.24,0.20,0.12,0.05,0.01)$. The long term-mean was subtracted and the time series further de-trended until the records clearly showed no trends when linear regression technique and the 'Students $t$ ' test were applied. When trends in the data exist over time, the first structure often captures them. The purpose of this analysis is to find spatial and temporal correlations independent of trends and thus de-trending data before applying the analysis.

\section{Results and discussion}

\subsection{Delineation of East Africa into Climatic Zones based on Decadal Rainfall Variability}

Table 1 gives the summary of results obtained from rotated VARIMAX solutions. Using the Scree test; Kaiser's criterion and North et al. (1982) sampling errors methods, nine PCA modes were significant for the MAM season. These accounted for $92 \%$ of total March - May decadal rainfall variance and thus was used for further analyses. Results from the second rainfall season of OND indicated seven modes accounting for $91.3 \%$ are significant. During the Northern Hemisphere summer of June to August season, most of the region is dry except the western equatorial and coastal sectors influenced by Lake Victoria and Indian Ocean respectively. Eight PCA modes accounting of $89.9 \%$ were significant during this season.

Figure 1 show 9, 7 and 8 unique climatologically homogeneous zones delineated for the MAM, OND and JJA seasons, respectively, using decadal rainfall records for the three countries of the study region. We group together stations with common characteristics into homogeneous regions using spatial patterns of the dominant PCA modes. The PCA statistics (Communality) at each individual zone is therefore used to identify a representative station for each zone, which is used for further analyses (Gregory, 1975; Ogallo, 1988, 1989; Basalirwa, 1991; Indeje, 2000; Okoola, 1996; ICPAC, 1999). For example, correlation between the stations with highest communality in every cluster is computed and this helps in the mapping of stations into zones. Correlation coefficients values as high as 0.94 are observed between Dar-es-Salaam International Airport (DIA) and stations within zone 5 during OND season (Figure 1b). To facilitate discussion of the regions, Figure 4 presents the anomaly of decadal precipitation across some stations in each of the delineated homogenous regions. Determining the spatial form of these signals was the primary purpose of the PCA. The 9 significant modes of variability passed both Scree and Kaiser's criterion tests but the eigen values were indistinguishable at 95\% confidence level using North et al. (1982) sampling error test.

Figure 2 shows an example of ten years cycle dominant in most rainfall records that were subjected to spectral analysis. The spectral peaks are significant at $95 \%$ confidence level when both white and red noise hypotheses are tested. The ten years dominant cycles demonstrate the dominance of decadal variability in rainfall patterns over East Africa. There are, however, significant differences in the amplitudes and spectral bands of the spectral peaks from the various regions, which signified some differences in the impacts of the decadal variability of various parts of East Africa due to the modification of the complex regional climate systems.

42 Figure 3, however, depicts long-term linear trends towards negative values, which are 43 detectable in most sub-regions. When linear regression technique and the 'Students t' test 
for testing if there is any significance in the trend are applied, there were no statistically significant trends detected. Results of the study further showed wet and dry decades recurring with approximately ten years cycle (Figure 4) and sometimes extend over large areas of the region.

\subsection{Linkages between regional decadal rainfall variability patterns and global SSTs}

Table 2 provides the two main summary statistics of the SVD analysis obtained when the three global basins were separately analyzed with the three rainfall seasons of the region. These statistics provide a measure of the strength of the relationship between the two fields. The first statistic, the Squared Covariance Fraction $\left(\mathrm{SCF}_{\mathrm{k}}\right)$, where $\mathrm{k}$ is the mode number, provides the percentage of the total squared covariance between the two fields explained by the SVD mode, and is proportional to the square of its singular value. This is a measure of the relative importance of the SVD mode in the relationship between the two fields. It should be noted that only the first three significant covariability modes of the squared covariance is shown in Table 2 . The second statistic is the correlation coefficient $\left(\mathrm{r}_{\mathrm{k}}\right)$ between the two time series that represent the temporal variations of the mode in the two fields. It is a measure of the similarity between the time variations of the patterns of the two fields, or how strongly the two fields are related to each other with respect to time (significant at the $5 \%$ level) for the first three modes.

We investigate linkages between smoothed SST and decadal rainfall anomalies using SVD to establish existence of covariance amongst East Africa rainfall and the specific global Ocean basin temperatures.

\subsubsection{The three Oceans versus MAM modes}

Figure 5 shows the spatial and temporal patterns of the first SVD mode of MAM rainfall and Indian Ocean SST that accounted for $49.9 \%$ of the total square covariance. This mode is characterized by large pool of positive warming over western and northern Indian Ocean while negative loading are over south-eastern Indian Ocean (Figure 5a). The corresponding precipitation pattern shows positive loadings over most parts of the region especially where MAM rains are dominant (Figure 5b). It identifies the warming trend signal in the SSTs with strong positive loadings throughout the central Indian Ocean. A similar SST loading pattern has been reported by Smith and Reynolds (2003). The correlation coefficient of time series of the expansion coefficient of both SST and rainfall fields is 0.73 (Figure 5c).

This first SVD mode is characterized by some east-west and north-south dipole patterns that are associated with much rainfall over most parts of the region. Some previous studies have shown strong positive SST anomalies over western Indian Ocean and negative SST anomalies off the Indonesia coast that has been referred to it as the positive Indian Ocean Dipole (IOD) Mode (Webster et al., 1999; Saji et al., 1999; Yu and Rienecker, 2000; Saji and Yamagata, 2003a; Black et al., 2003; Black, 2004; Hastenrath and Polzin, 2003, 2004; Behera et al., 2005; Singhrattna et al., 2005; Owiti, 2005; Tozuka et al., 2007; Meyers et al., 2007; Huang and Shukla 2007, Garci'a-Garci'a et al., 2011, and Becker et al. 2011). 
The second SVD mode (SVD-2) that accounted for 14.8\% variance has negative coherence loadings centered on the central equatorial Indian Ocean and positive loading over the south-western parts of the ocean basin (Figure 6a). This mode is also characterized by negative loadings over the northern sector while positive loading is confined over the southern sector of the sub-region (Figure 6b). It also showed stronger decadal trend mode (correlation coefficient, $r=0.64$ ) in time series of expansion coefficient (Figure 6c) compared to SVD-1 mode. Such a pattern in the Indian Ocean was observed in Nyakwada (2009) and has been attributed to the mean seasonal SST pattern over the ocean when the overhead sun crosses the equator.

The third mode (SVD-3), which accounted for 9.9\% of the variance showed positive loadings over the entire Indian Ocean with the highest loadings concentrated in the area between $20^{\circ} \mathrm{N}$ and $15^{\circ} \mathrm{S}$ (not shown). This pattern is associated with strong positive loadings for rainfall over the eastern sector and negative loadings over western sector of the region with strong decadal signal in the time series of expansion coefficients. It is worth noting that although this mode explains relatively low covariance, it was still able to display strong decadal variability for the MAM rainfall season (Rao and Yamagata, 2004; Rao and Behera, 2005; Rao et al., 2007).

The results from SVD analysis discussed above confirm the complexity of rainfall variability over East Africa during MAM rainfall season. SVD has however delineated three modes that could give more insight into the modes of decadal rainfall variability over the region. The dominance of the modes representing zonal SST variability in the Indian Ocean, which may be associated with the strong influence of this ocean on the climate of the region has been indicated and consistent with observation analyses by many other authors including Okoola (1996); Goddard and Graham (1999); Mutai (2003); Nyakwada (2009) among others.

Similarly, the influence of the Atlantic Ocean on MAM decadal rainfall was investigated using SVD technique. Moisture influx from the ocean is associated with enhanced westerly circulation that also favours the incursions of moisture from the always wet tropical forests of Congo, Democratic Republic of Congo (DRC) and other central African countries. The SST variability in the Atlantic Ocean reaches its maximum in the period January to May (Wu et al. 2007). The results of the analysis showed SVD-1 mode accounting for about $43 \%$ of the total covariance, and is characterized by a meridional dipole like pattern with negative loadings over the northern equatorial Atlantic Ocean and positive loadings over the southern equatorial Atlantic basin (Figure 7a). The rainfall component of this mode showed a southeastern - northwestern dipole pattern with negative loadings over the south-eastern sub-sector while positive loading over north-western segment of the region (Figure 7b). The time series of expansion of SVD coefficients of both rainfall and SST anomalies has a correlation coefficient of 0.97 (Figure $7 \mathrm{c}$ ) that also shows some trends and enhancement of the decadal amplitudes in some years (Figure 7c).

The SVD-2 mode between MAM rainfall and Atlantic Ocean SST fields explains 23\% of the total covariance (Table 2). Large coherent positive loadings over the equatorial Atlantic Ocean (Figure 8a) are observed to be in association with large positive loading in most 
parts of the regions where MAM rainfall is significant (Figure 8b). The time series of expansion coefficients of this mode has a correlation of 0.98 significant at $95 \%$ confidence level. The time series further showed strong decadal variation with strong positive phases during mid 1960s and early 1980s.

The third mode for MAM rainfall and Atlantic Ocean SST that explains $12.8 \%$ of the total covariance is occasioned by inter-hemispheric positive loading over the southern Atlantic Ocean and negative loading over northern hemisphere with centre at $\left(50^{\circ} \mathrm{W}-35^{\circ} \mathrm{W}, 4^{\circ} \mathrm{S}\right.$ $15^{\circ} \mathrm{N}$ ) of the basin. The regional rainfall variability associated to this mode has positive and negative loadings in the southern and northern sub-region respectively. This pattern was observed to be more or less opposite to that of SVD-2 mode in Figure 8b. The time series of expansion coefficients of this mode has increasing trend in the 1960s and 1970s decades. Lindzen and Nigam (1987) observed similar pattern in their study and indicated that such gradients have a stronger influence on the climate in the tropical regions. This mode displayed both zonal and meridional SST variability that has been observed to have significant influence on the rainfall over western Africa (Wasilla, 2007).

Analysis of MAM rainfall and Pacific Ocean SSTs showed a rather stronger coupling compared to other basins. This is manifested in the first three modes contributing to about $79 \%$ of the decadal rainfall covariance. The SVD-1 mode that contributed about $38 \%$ of the total covariance is characterized by warming over the eastern and cooling over western Pacific Ocean, reminiscent of El Niño SST pattern (see e.g., Garci'a-Garci'a et al., 2011, Forootan et al., 2012). SVD-2 Mode for the Pacific contributed to about 25\% of the covariance and is also characterized by strong negative loadings over the eastern and positive loadings over western equatorial Pacific Ocean. This is the cold phase of La Niña SST pattern that is associated with deficient seasonal rainfall over most parts of the region (Ropelewski and Halpert, 1987; Indeje 2000; Mutemi, 2003). Njau (2006) observed that most of the severe droughts over Kenya were experienced during the MAM rainfall season preceding El-Niño event. The SVD-3 which contributes about $17 \%$ of the total covariance is characterized by unique negative loadings over the eastern and western with positive loadings over the central equatorial Pacific Ocean.

\subsubsection{The three Oceans versus OND modes}

We now discuss the results obtained when the three global oceans were independently analyzed with OND decadal rainfall. The results show stronger coupling between the three oceans and OND decadal rainfall compared to the MAM rainfall. The three leading SVDcoupled modes explain greater than $80 \%$ of the squared covariance compared to $75 \%$ for the MAM rainfall. Figure 9 shows the heterogeneous correlation patterns for the first mode in the SVD expansion for the Indian Ocean SST anomaly and OND decadal rainfall from 1954 to 1983 (30 years WMO climatology). Each map represents the correlation between the expansion coefficients of one field and the grid point anomaly values of the other field. The heterogeneous pattern for the first SVD mode (Figure 9a) has two prominent features. The primary characteristic is the warming of the southwestern ocean as indicated by the positive loadings and cooling in southeastern ocean, mainly south of the equator. Secondly, this corresponds to negative loading patterns of rainfall over the southern sector and 
positive loading over the northern sector of the region. Mode- 1 explains $65 \%$ of the total coupling covariance which seems to represent the mean seasonal patterns of SST over the ocean consistent with the studies of Behera et al. (2005), Schreck and Semazzi (2004), Terray and Dominiak (2005), and Tozuka et al. (2007). The time series of expansion of this mode showed a decreasing trend with correlation coefficient of 0.87 during the period of the study.

The heterogeneous pattern for the second SVD mode has spatial patterns exhibiting large coherent negative loading over the central equatorial Indian Ocean with small positive tongue over the Indo-Pacific Oceans (Figure 10a). This signal is generally associated with negative loading patterns over most parts of the region especially over areas that receive substantial rainfall during OND season (Figure 10b). This mode shows that the large-scale cooling of the ocean is associated with dry decades over the region. Harrison and Carson (2007); Ihara et al., (2008); and Nyakwada (2009) observed similar patterns over the Ocean in their respective studies. The time series of expansion coefficients of mode- 2 has correlation coefficient of 0.98 with significant decreasing decadal trend since 1960s.

Figure 11 shows the heterogeneous correlation patterns for the first mode in the SVD expansion for the Atlantic SST anomaly and OND rainfall (Table 2). The Atlantic Ocean is to the west of the region of study and moisture influx from the ocean is associated with enhanced westerly circulation that also favours the incursions of moisture from the always wet tropical forests of Congo, DRC and other central African countries. The SST variability in the Atlantic Ocean reaches its maximum in the period January to May (Wu et al. 2007). The first three SVD modes for Atlantic Ocean SST and October-December seasonal rainfall accounted for about $84 \%$ of the total square covariance. Mode-1 (47.8\%) is characterized by a meridional dipole like pattern with negative loadings over the northern equatorial Atlantic Ocean and positive loadings over the southern equatorial Atlantic basin (Figure 11a). The OND rainfall component of this mode is characterized by south-eastern - northwestern dipole pattern with negative and positive loadings respectively over the sub-sector (Figure 11b). The time series of expansion of this mode has a correlation coefficient of 0.97 and also shows some enhanced decadal modes (Figure 11c).

The spatial patterns observed for mode-2 seems to be opposite to that observed for SVD-1 mode for the same basin (Figure not shown). This shows that a change in the interhemispheric loading patterns in the Ocean causes corresponding change in the spatial and temporal regional rainfall loading patterns. For instance whenever there is negative loading in the northern Atlantic Ocean and positive in the south, the regional rainfall pattern is associated with positive loading in the northern sector and negative loading in the southern sector and vice versa. Similar changes are also true for the time series expansion coefficients of the two fields.

41

This suggests that the large scale changes in the global basins SSTs have significant influence on regional decadal climate variability. This emphasizes the importance of the ocean currents and the associated SST patterns in the study of climate variability and prediction. Strong relationship between ocean currents and climate have been established to be the major influence of regional climates (Valsala and Ikeda, 2007; Cai and Cowan, 
2007; Keller et al., 2007). Whenever there is enhancement of ENSO, this mode has always been manifested (and it is also linked to the North Atlantic Oscillation (NAO) (Li et al., 2007; Wu et al., 2007).

The results on coupling between the Pacific Ocean and the October-December rainfall at decadal time scale over the region is summarized in Table 2 and also spatially shown by Figure 12a. Although Pacific is the furthest ocean from the region, it has some strong teleconnections to the East African climate, especially during ENSO and other years with large SST anomalies (Ogallo and Suleiman, 1987; Ropelewski and Halpert, 1987; Nicholson and Kim, 1997; Wassila et al., 1999; Wang and Eltahir, 1999; Indeje, 2000; Indeje et al., 2000; Schreck and Semmazzi, 2004; Korecha and Barnston, 2007). Circulation anomalies in Pacific Ocean have significant influence on Indian and Atlantic Oceans and the surrounding land areas (Wolter, 1987, Terray and Dominiak, 2005) including East African rainfall.

The first three modes for the Pacific SST and OND rainfall accounted for about $80 \%$ of the decadal rainfall covariance. The heterogeneous pattern for the first SVD mode that contributes about $39 \%$ of the total covariance mainly reveals the ENSO-like pattern in the central equatorial Pacific (figure not shown). The impact of this mode is observed to have similarity to mode-1 of the Indian Ocean on East African rainfall (Figure 5b). This may be due to close responses of the circulation amongst the three oceans (Burroughs 1999). It has been shown that ENSO is linked to the Indian Ocean variability through the modulation of walker circulation (Xie et al., 2002; Saji and Yamagata, 2003b; Krishnamurty and Kirtman, 2003; Kug et al., 2005; Kug and Kang, 2006; Kug et al., 2006).

The SSTs over the southern Indian Ocean during the December to February have been observed to influence climate shift in the Indian and Pacific Oceans and thus predictors of El Niño (Terray and Dominiak, 2005). The SVD-2 Mode of the basin and OND rainfall (28\% of covariance) is characterized by the La Niña-like SST pattern with large negative loadings over the eastern central equatorial Pacific Ocean and positive loading over the western equatorial Pacific Ocean (Figure 12a). Such anomaly pattern is associated with negative loading over the region that causes depressed rainfall in the region (Figure 12b). The time series exhibits strong decadal variability with a long-term change toward higher values in 1962-70. The relative dry decade of 1960/1970 in the region noted by Omondi (2005) is reflected in the mode 2 time series.

\subsubsection{The three Oceans versus JJA modes}

The June-August (JJA) season constitute the third rainy season when western and coastal parts of the region receive substantial amount of rainfall. Parts of the equatorial sector, covering northern Tanzania, western and coastal areas generally exhibit a trimodal rainfall regime centered on MAM, JJA and OND seasons. In Table 2, a summary of results for the three basins coupling with JJA decadal rainfall are given with the first three leading modes accounting for about $87 \%$ of the covariance. SVD mode- 1 is characterized by a zonal dipole mode with pools of negative and positive loadings observed over the western and eastern equatorial Indian Ocean (Figure 13a) associated with depressed decadal rainfall over all parts of the region (Figure 13b). Time series of expansion of the coefficients demonstrates 
strong decadal variations in both time series with expansion coefficient of 0.98 (Figure 13c).

A rather interesting result presented in Figure 14a for SVD mode-1 when coupling between the JJA decadal rainfall and Atlantic Ocean accounted for 38.6\% of the total covariance. An inter-hemispheric dipole with positive loading over the southern $\left(0^{\circ} \mathrm{E}-15^{\circ} \mathrm{E}, 30^{\circ} \mathrm{S}-15^{\circ} \mathrm{S}\right)$ and the negative pole in the northern part of the tropical Atlantic Ocean (Figure 14a) with strong decadal signal in time series of expansion coefficients (significant correlation of 0.99) was delineated (Figure 14c). This pattern can therefore be linked to the possibly strong JJA decadal rainfall variability over the region (Figure 14b). The second dominant SVD-2 explains $29.2 \%$ of the total JJA rainfall and SST covariance. Its spatial characteristic is opposite to that of OND rainfall and Atlantic Ocean (Figure 11b) hence not shown in this study. There are, however, some differences in the magnitudes and spatial spread over some areas with high positive / negative loadings.

These results signify the importance of Atlantic Ocean modes on decadal rainfall over East Africa. The characteristics of the SVD modes are closely associated with some climate extremes affecting the region. These could be associated with the implications of these modes on the circulations, energy, and moisture induced by the ocean, and other inland rain generating systems. Barnston et al., (1996) demonstrated that the time-space behaviour of the SST field alone influences the JJA seasonal rainfall over the region both on interannual and inter-decadal time-scales. Other similar results with JJAS season have been documented, e.g., by Gissila et al., (2004); Segele and Lamb (2005); Korecha and Barnston (2007); Zewdu et al (2009) among others.

The result of SVD mode one for the Pacific Ocean and JJA rainfall fields showed ENSO-like pattern discussed in the previous section. However, SVD-2 mode is characterized by large pool of positive SST anomalies over the central equatorial Pacific and negative SST anomalies in the equatorial western and eastern parts of the basin (Figure 15a). The corresponding impact of this mode on regional rainfall is positive loading over western equatorial parts of the region and negative loading over the eastern highlands (Figure 15b). Major warming events for this mode take place over the Central Pacific Ocean unlike the eastern/western Pacific of typical El Niño/La Niña evolution. Similar pattern in tropical Pacific SST variability mode was observed and referred to as trans-Niño index (Trenberth and Stepaniak, 2001; Trenberth et al., 2002) and later by Ashok et al., (2007) who termed it 'El Niño Modoki'. Cold SST anomalies (SSTA) are observed on both sides along the equator (Trenberth and Stepaniak, 2001; Trenberth et al., 2002, Ashok et al., 2007; Meyers et al., 2007; Ashok et al., 2009; Hye-Mi Kim, et al., 2009) and this is associated with enhanced and depressed rainfall over western and eastern sectors respectively of East Africa region. El Niño Modoki involves ocean-atmosphere coupling processes, which include a unique tripolar sea level pressure pattern during the evolution, analogous to the Southern Oscillation in case of El Niño (Ashok et al., 2007; Meyers et al., 2007; Ashok et al., 2009; Hye-Mi Kim, et al., 2009). This anomalous warming event is different from conventional El Niño events but both take place in equatorial Pacific. 
The results from SVD analyses have therefore demonstrated that although decadal rainfall variability modes are generally common at all locations, some strong signals were only restricted to specific areas. These signals were evident for all seasons over the entire region. It is a fact that some climate extremes experienced over the region such as floods of the early 1960s, 1997/98 and droughts of 1970s and early 1980s that extended over most parts of the region had decadal finger prints. The strong coupling between global basins and decadal rainfall can provide new prediction tools that are important for decadal rainfall prediction. This again can contribute to the formulation and improvement of prediction skills in numerical modeling and early warning several lead times ahead.

\section{Summary and conclusions}

The primary focus of this study was to investigate the dominant spatial and temporal decadal rainfall variability modes over East Africa region and their linkages to decadal variability modes of the specific global oceans. The first investigation involved the use of RPCA and simple correlation analysis approaches to delineate East Africa region into zones with similar modes of decadal rainfall variability. This analysis was mainly to group together stations with common decadal rainfall characteristics into homogeneous zones. The stations highly correlated with each other were identified as representative stations for every zone used for the analyses in the study. Each observed rainfall record for the delineated representative station was thereafter subjected to spectral analysis to demonstrate the dominance of ten years cycles. We applied SVD to evaluate the existence of covariance amongst regional rainfall and the individual global basins SSTs. VARIMAXRPCA analysis delineated nine, seven and eight unique climatologically homogeneous zones for March-May (MAM), October-December (OND) and June - August (JJA) seasons respectively when smoothed rainfall records are used. It is also evident from our analysis that ten years cycle was dominant in most rainfall records with significant differences in the amplitudes and spectral bands of the spectral peaks from the various regions. This could be a reflection of the complex nature of the regional climate systems that include complex topography and large water bodies that include Lake Victoria. The results obtained from the teleconnections of the regional decadal rainfall variability patterns to the global SSTs using SVD analysis showed that:

1. Decadal variability of the SSTs in the Pacific, Atlantic and Indian Oceans all have significant influence on regional decadal rainfall variability.

2. Significant coupling of the SSTs and rainfall fields were observed with high values of SCF explained by the first three modes for each of the three oceans.

3. Generally, the study revealed that even when decadal variability of one of the oceans contributed most of the variance of decadal rainfall variability, the roles of the other two oceans were still very significant. This signifies the close interaction among the global oceans SSTs and the complex regional scale climate processes. The first three SVD modes of the basin SSTs and decadal rainfall accounted for over 75\% of the total square covariance for all the seasons, with statistically significant expansion coefficients of time series of the SVD mode of the two fields' anomalies. 
4. The SVD analysis for MAM rainfall season with Indian Ocean SST showed the first dominant mode accounting for $49.9 \%$ of the total square covariance and this was influenced mainly by the east/west zonal mode over the Indian Ocean.

5. Results for SVD analysis for OND rainfall season with Pacific Ocean SST showed the first dominant mode accounting $39.2 \%$ of the total square covariance. Decadal rainfall variability for this season was dominantly characterized by decadal variability modes of the ENSO phenomenon over the equatorial Pacific Ocean.

6. SVD analysis for the third rainfall season of June - August and the Atlantic Ocean SST showed the first dominant mode accounting for $38.6 \%$ of the total square covariance. The key modes of variability that seemed to drive the June -August rainfall significantly was the inter-hemispheric tropical Atlantic variability with meridional dipole pattern in the Atlantic Ocean. A unique tripolar mode of variability observed during this season was characterized by large pool of positive loading over the central equatorial Pacific and negative loadings in the equatorial western and eastern parts of the basin. This mode is associated with wet decades over western parts of the region and dry decades over the eastern sectors of the region.

The knowledge of extreme climate variations at decadal timescale gained from this study is useful for planning and decision making of long term climate risk management strategies for sustainable socioeconomic development. It can also provide means of using ocean variability modes to predict future decadal rainfall variability. Availability of timely and accurate climate information can provide useful tools for forward planning to reduce the vulnerability and risks of the hydro-meteorological hazards that currently are prevalent in the region. This lead time of the early warning is important for the general planning and management of the disaster risk reduction. 
Page 19 of 47

\section{Acknowledgements}

2 We are grateful to the IGAD Climate Prediction and Application Centre (ICPAC) through the

3 Director for the scholarship and computer resources that made the pursuance of this 4 research study possible. The Kenya Meteorological Department (KMD), Tanzania 5 Meteorological Agency (TMA), and Uganda Meteorological Department (UMD) provided the 6 rainfall data used in this study. 


\section{Table Captions}

Table 1: VARIMAX-RPCA results of homogeneous group of stations extracted by each mode

of the decadal MAM, OND and JJA rainfall

Table 2: Summary of some statistics from SVD analysis for decadal seasonal rainfall and the various global Ocean SSTs

Table 3: Assessment of the skill for regression models

\section{Figure Captions}

10 Figure 1: Homogeneous climatic zones over East Africa obtained from combined PCA and 11 simple correlation analyses using March-May (MAM), October-December (OND) and June12 August (JJA) decadal rainfall variability. Blue areas in the figure represent water bodies of 13 Lake Victoria and Turkana)

14 Figure 2: Spectral analysis of the smoothed March - May seasonal rainfall for zone 8 as 15 represented by Mbarara

16 Figure 3: Smoothed March - May rainfall anomalies depicting decadal variability with small

17 percentages of the variance of the signals that are not statistically significant over Voi in

18 Kenya

19 Figure 4: Graphical plots of decadal rainfall variability for some representative stations

20 over East Africa region during all the three seasons

21 Figure 5: Spatial patterns of the first SVD mode accounting for $49.9 \%$ of the covariance for (a) Indian Ocean SST, (b) MAM rainfall presented as homogeneous correlation maps (c) Time series of expansion coefficients (s1) of the first SVD mode for March - May rainfall and Indian Ocean SST anomalies

Figure 6: Spatial patterns of the second SVD mode accounting for $14.8 \%$ of the covariance for (a) Indian Ocean SST, (b) MAM rainfall presented as homogeneous correlation maps (c) Time series of expansion coefficients (s2) of the second SVD mode

Figure 7: Spatial patterns of the first SVD mode accounting for $43 \%$ of the covariance for (a) Atlantic Ocean SST, (b) MAM rainfall presented as homogeneous correlation maps (c) Time series of expansion coefficients (s1) of the first SVD mode

Figure 8: Spatial patterns of the second SVD mode accounting for $23 \%$ of the covariance for (a) Atlantic Ocean SST, (b) MAM rainfall presented as homogeneous correlation maps (c) Time series of expansion coefficients (s2) of the second SVD mode

34 Figure 9: Spatial patterns of the first SVD mode accounting for $65 \%$ of the covariance for (a) Indian Ocean SST, (b) OND rainfall presented as homogeneous correlation maps (c)

36 Time series of expansion coefficients (s1) of the first SVD mode

37 Figure 10: Spatial patterns of the second SVD mode accounting for $16.5 \%$ of the covariance 38 for (a) Indian Ocean SST, (b) OND rainfall presented as homogeneous correlation maps (c) Time series of expansion coefficients (s2) of the second SVD mode 
1 Figure 11: Spatial patterns of the first SVD mode accounting for $47.8 \%$ of the covariance for 2 (a) Atlantic Ocean SST, (b) OND rainfall presented as homogeneous correlation maps (c) 3 Time series of expansion coefficients (s1) of the first SVD mode

4 Figure 12: Spatial patterns of the second SVD mode accounting for $28 \%$ of the covariance 5 for (a) Pacific Ocean SST, (b) OND rainfall presented as homogeneous correlation maps (c)

6 Time series of expansion coefficients (s2) of the second SVD mode

7 Figure 13: Spatial patterns of the first SVD mode accounting for $61.1 \%$ of the covariance for 8 (a) Indian Ocean SST, (b) JJA rainfall presented as homogeneous correlation maps (c) Time 9 series of expansion coefficients (s1) of the first SVD mode

10 Figure 14: Spatial patterns of the first SVD mode accounting for $38.6 \%$ of the covariance for 11 (a) Atlantic Ocean SST, (b) JJA rainfall presented as homogeneous correlation maps (c) 12 Time series of expansion coefficients (s1) of the first SVD mode

13 Figure 15: Spatial patterns of the second SVD mode accounting for $20 \%$ of the covariance 14 for (a) Pacific Ocean SST, (b) JJA rainfall presented as homogeneous correlation maps (c) 15 Time series of expansion coefficients (s2) of the second SVD mode 
Page 22 of $\mathbf{4 7}$

1 Table 1

\begin{tabular}{|c|c|c|c|c|}
\hline PERIOD & FACTOR & EIGENVALUE & $\begin{array}{c}\text { VARIANCE } \\
\text { EXTRACTED (\%) }\end{array}$ & $\begin{array}{l}\text { CUMULATIVE } \\
\text { VARIANCE (\%) }\end{array}$ \\
\hline \multirow{9}{*}{ MAM } & 1 & 7.3 & $\begin{array}{l}19.7 \\
\end{array}$ & $\begin{array}{l}19.7 \\
\end{array}$ \\
\hline & 2 & 6.9 & 18.6 & 38.3 \\
\hline & 3 & 5.9 & 15.9 & 54.2 \\
\hline & 4 & 4.2 & 11.4 & 65.6 \\
\hline & 5 & 3.0 & 8.1 & 73.7 \\
\hline & 6 & 2.3 & 6.4 & 80.1 \\
\hline & 7 & 1.8 & 5.0 & 85.1 \\
\hline & 8 & 1.2 & 3.3 & 88.4 \\
\hline & 9 & 1.1 & 2.9 & 91.3 \\
\hline \multirow{7}{*}{ OND } & 1 & 15.87 & 42.9 & 42.9 \\
\hline & 2 & 5.25 & 14.2 & 57.1 \\
\hline & 3 & 3.87 & 10.5 & 67.6 \\
\hline & 4 & 2.67 & 7.2 & 74.8 \\
\hline & 5 & 2.40 & 6.5 & 81.3 \\
\hline & 6 & 2.32 & 6.3 & 87.6 \\
\hline & 7 & 1.38 & 3.7 & 91.3 \\
\hline \multirow{8}{*}{ JJA } & 1 & 7.9 & 24.1 & 24.1 \\
\hline & 2 & 5.4 & 16.5 & 40.6 \\
\hline & 3 & 4.3 & 13.0 & 53.6 \\
\hline & 4 & 3.8 & 11.5 & 65.1 \\
\hline & 5 & 3.1 & 9.5 & 74.6 \\
\hline & 6 & 2.1 & 6.3 & 80.9 \\
\hline & 7 & 1.6 & 4.9 & 85.8 \\
\hline & 8 & 1.3 & 4.0 & 89.8 \\
\hline
\end{tabular}

3

4 
Page 23 of 47

Table 2

\begin{tabular}{|c|c|c|c|c|c|c|}
\hline Season & Oceans & $\begin{array}{c}\text { Mode } \\
(\mathrm{k})\end{array}$ & $\begin{array}{c}\text { Square } \\
\text { Covariance } \\
\text { fraction } \\
\text { (SCF) } \\
\end{array}$ & $\begin{array}{l}\% \text { of total } \\
\text { mode } \\
\text { covariance }\end{array}$ & $\begin{array}{c}\text { Cumulative } \\
\% \\
\text { covariance }\end{array}$ & $\begin{array}{c}\text { Correlation } \\
\text { coefficient } \\
\text { ( } \mathrm{r})\end{array}$ \\
\hline \multirow{9}{*}{ MAM } & \multirow[t]{3}{*}{ INDIAN } & 1 & 20.5 & 49.9 & 49.9 & 0.73 \\
\hline & & 2 & 6.1 & 14.8 & 64.7 & 0.64 \\
\hline & & 3 & 4.1 & 9.9 & 74.6 & 0.38 \\
\hline & \multirow[t]{3}{*}{ ATLANTIC } & 1 & 16.9 & 43.4 & 43.4 & 0.99 \\
\hline & & 2 & 9.0 & 23.1 & 66.5 & 0.98 \\
\hline & & 3 & 5.0 & 12.8 & 79.3 & 0.97 \\
\hline & \multirow[t]{3}{*}{ PACIFIC } & 1 & 38.6 & 37.8 & 37.8 & 0.99 \\
\hline & & 2 & 25.5 & 25.0 & 62.8 & 0.98 \\
\hline & & 3 & 17.0 & 16.7 & 79.4 & 0.88 \\
\hline \multirow{9}{*}{ OND } & \multirow[t]{3}{*}{ INDIAN } & 1 & 26.7 & 65.2 & 65.2 & 0.99 \\
\hline & & 2 & 6.8 & 16.5 & 81.7 & 0.98 \\
\hline & & 3 & 3.6 & 8.8 & 90.5 & 0.94 \\
\hline & \multirow[t]{3}{*}{ ATLANTIC } & 1 & 18.7 & 47.8 & 47.8 & 0.97 \\
\hline & & 2 & 9.0 & 23.1 & 71.0 & 0.94 \\
\hline & & 3 & 4.9 & 12.5 & 83.5 & 0.76 \\
\hline & \multirow[t]{3}{*}{ PACIFIC } & 1 & 40.0 & 39.2 & 39.2 & 0.99 \\
\hline & & 2 & 28.0 & 27.5 & 66.7 & 0.96 \\
\hline & & 3 & 13.8 & 13.6 & 80.3 & 0.94 \\
\hline \multirow{9}{*}{ JJA } & \multirow[t]{3}{*}{ INDIAN } & 1 & 25.1 & 61.1 & 61.1 & 0.98 \\
\hline & & 2 & 6.9 & 16.8 & 78.0 & 0.96 \\
\hline & & 3 & 3.6 & 8.7 & 86.6 & 0.94 \\
\hline & \multirow[t]{3}{*}{ ATLANTIC } & 1 & 15.1 & 38.6 & 38.6 & 0.99 \\
\hline & & 2 & 11.4 & 29.2 & 67.9 & 0.97 \\
\hline & & 3 & 5.5 & 14.1 & 82.0 & 0.88 \\
\hline & \multirow[t]{3}{*}{ PACIFIC } & 1 & 43.0 & 42.1 & 42.1 & 0.99 \\
\hline & & 2 & 20.4 & 20.0 & 62.1 & 0.97 \\
\hline & & 3 & 15.6 & 15.3 & 77.4 & 0.85 \\
\hline
\end{tabular}

$2 r$ is the correlation coefficient between the expansion coefficient of SSTs and seasonal rainfall 3 modes

4

5

6 


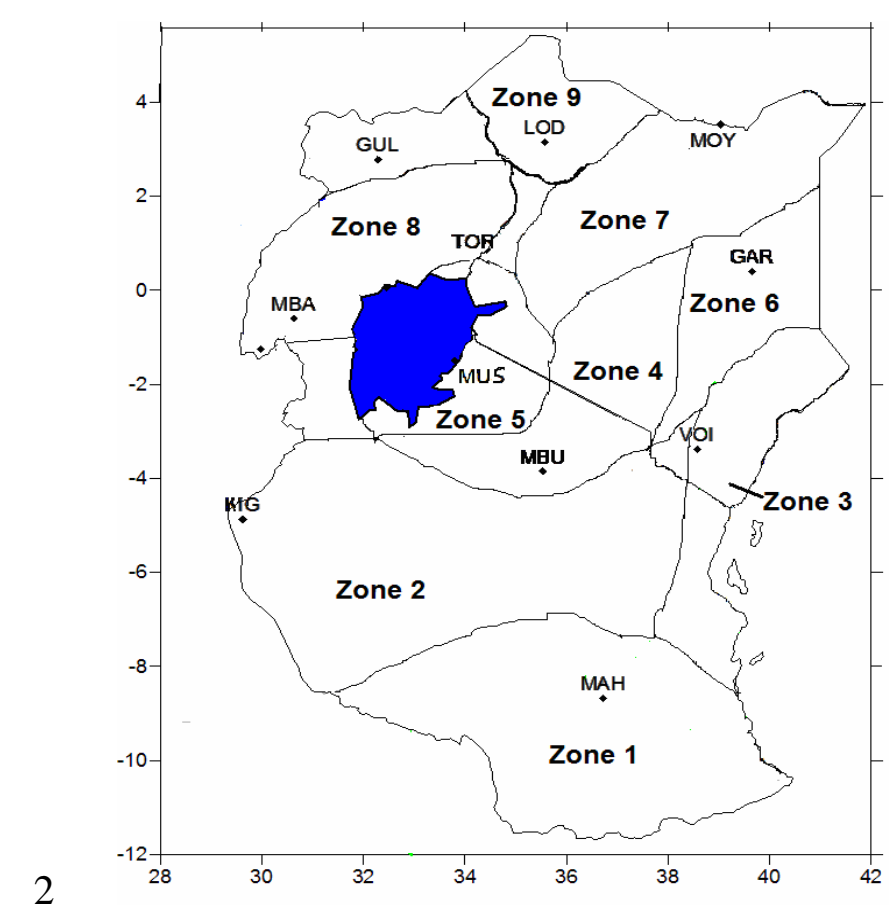

3 (a) MAM season

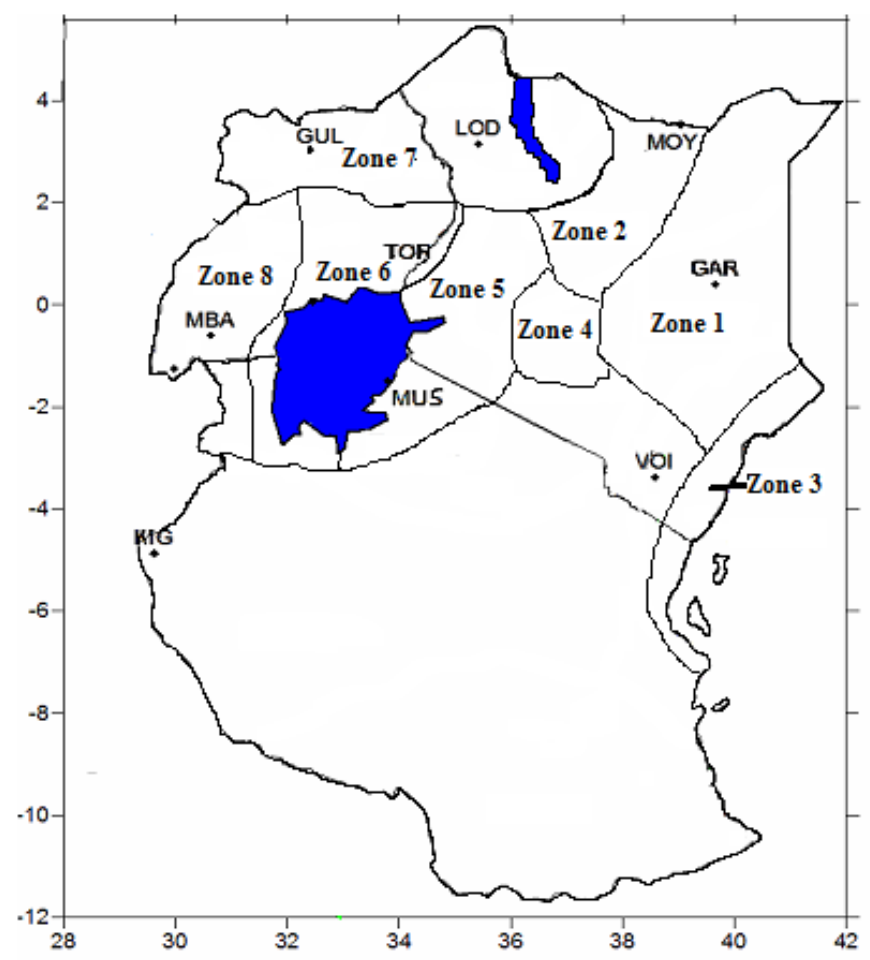

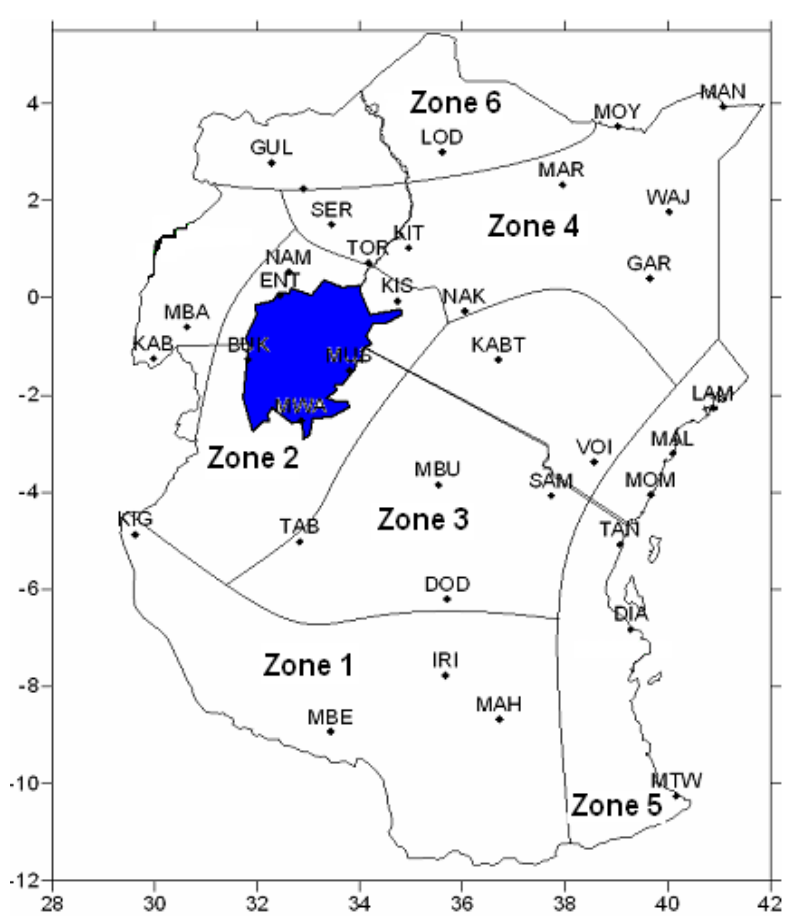

(b) OND season

\section{(c) JJA season}

6 Figure 1 
Page $\mathbf{2 5}$ of $\mathbf{4 7}$

1

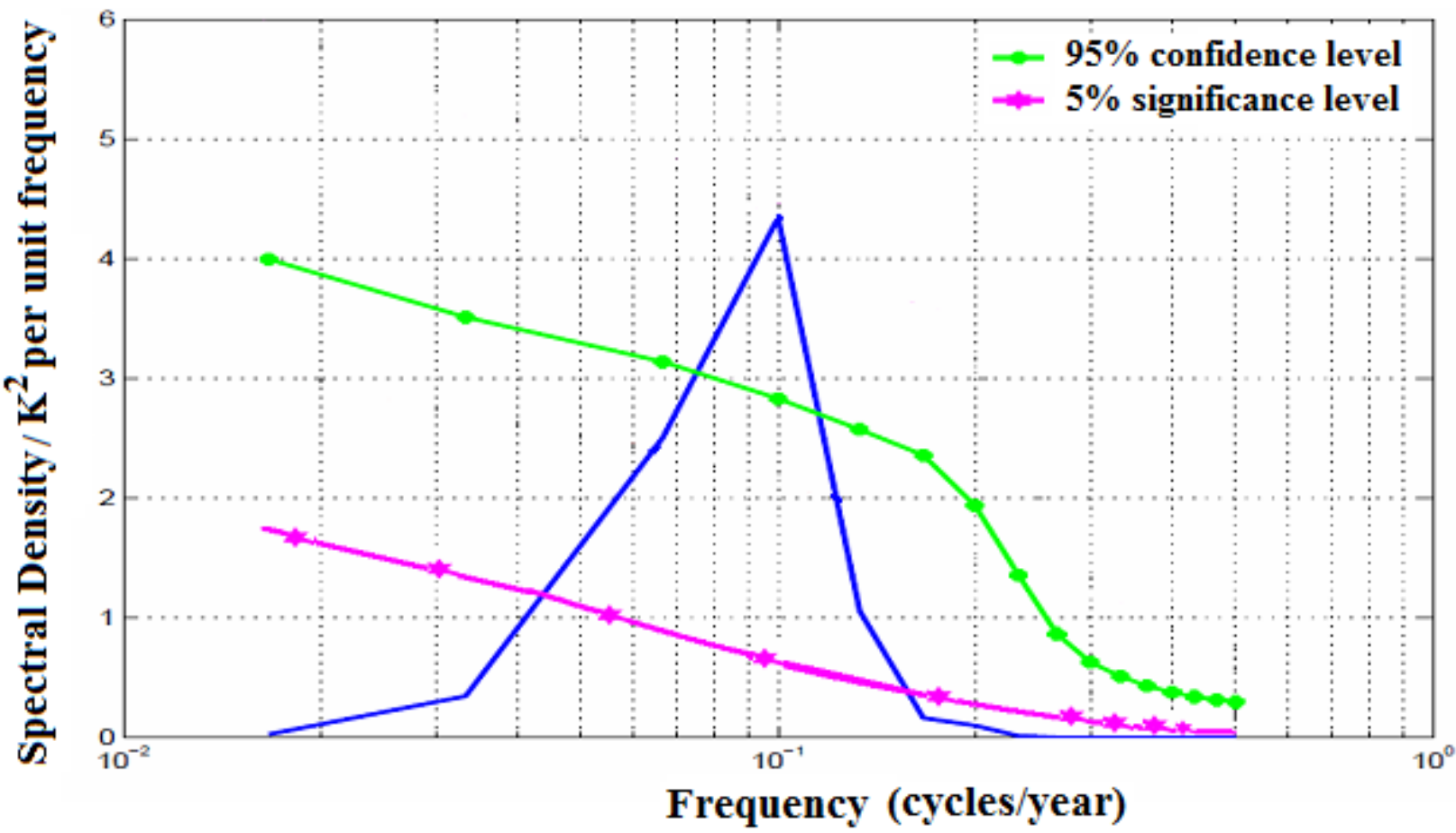

2
3

Figure 2

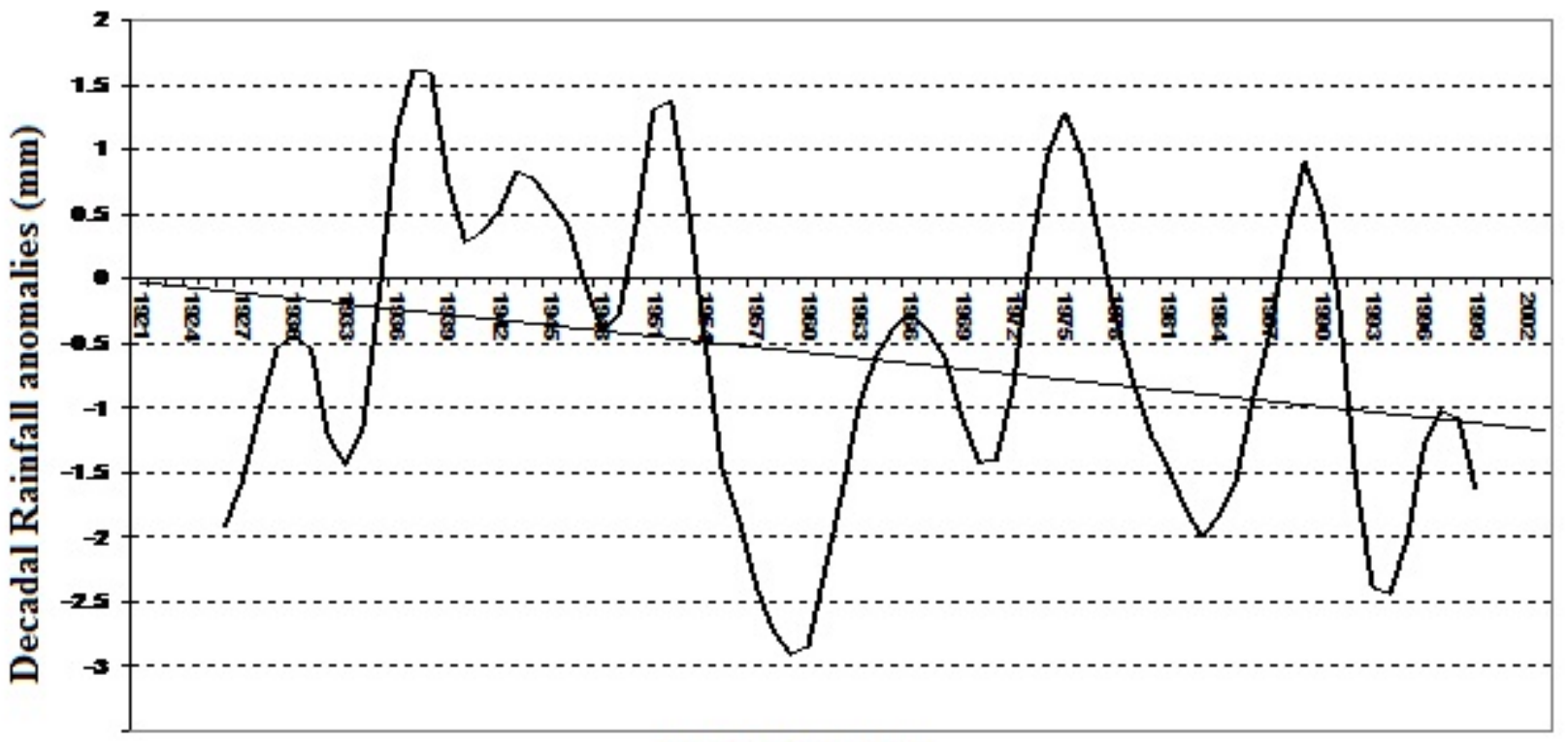

Period in years

Figure 3

8

9

10

11 
Page 26 of $\mathbf{4 7}$

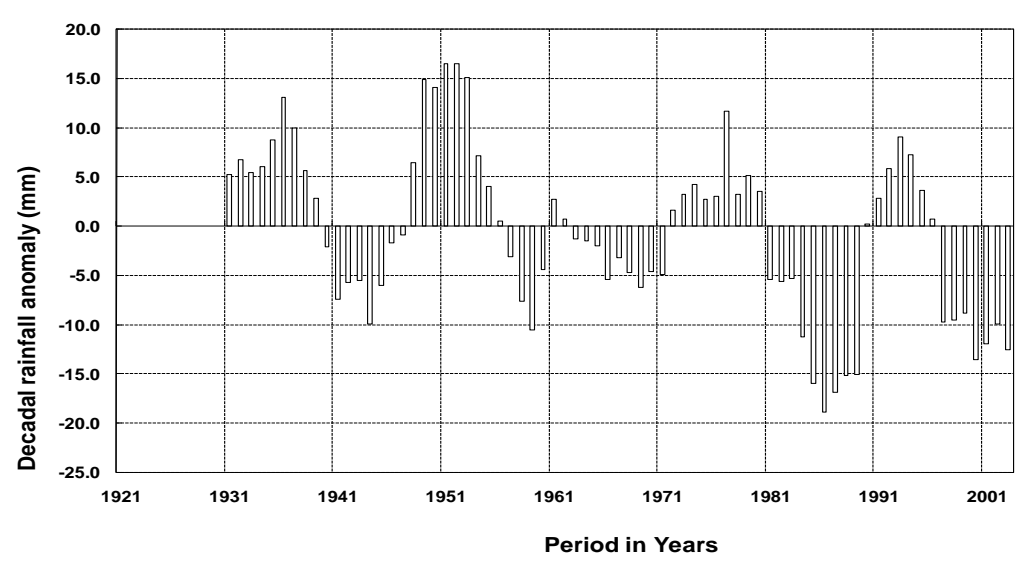

(i) Zone 1 (Iringa) for MAM

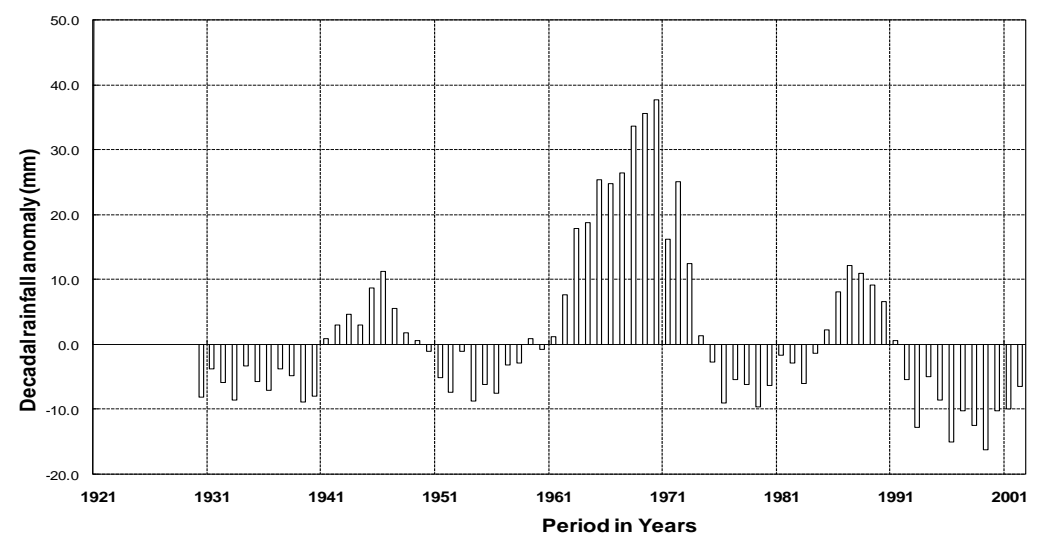

(iii) Zone 3 (Mbulu) for OND

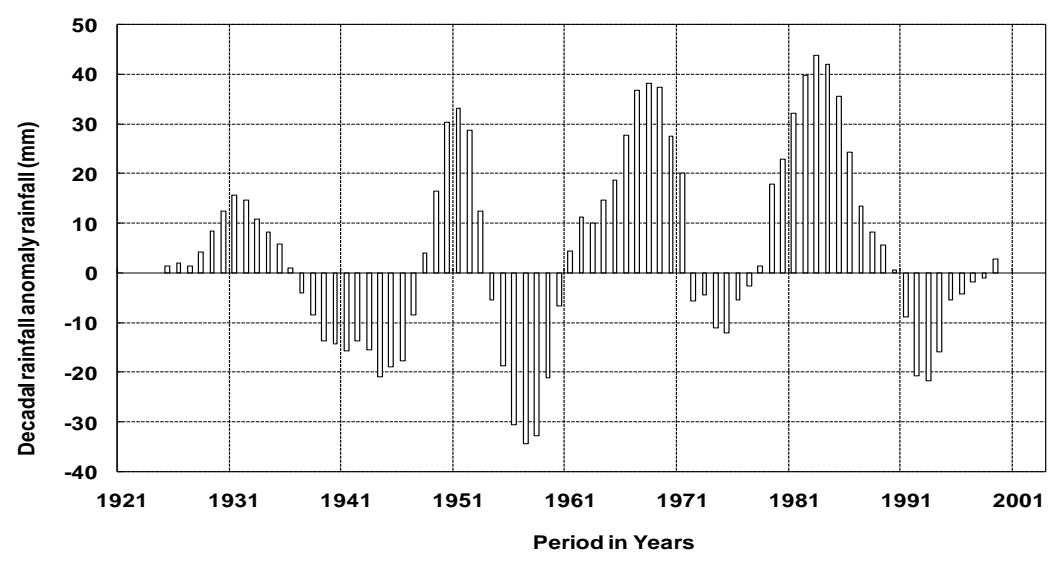

(ii) Zone 2 (Bukoba) for OND

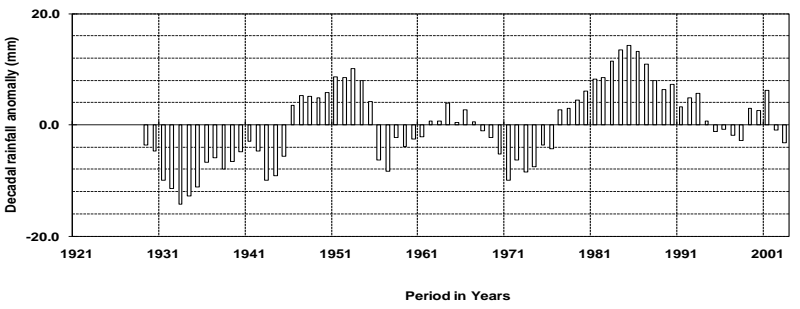

(iv) Zone 4 (Kisumu) for JJA

Figure 4 

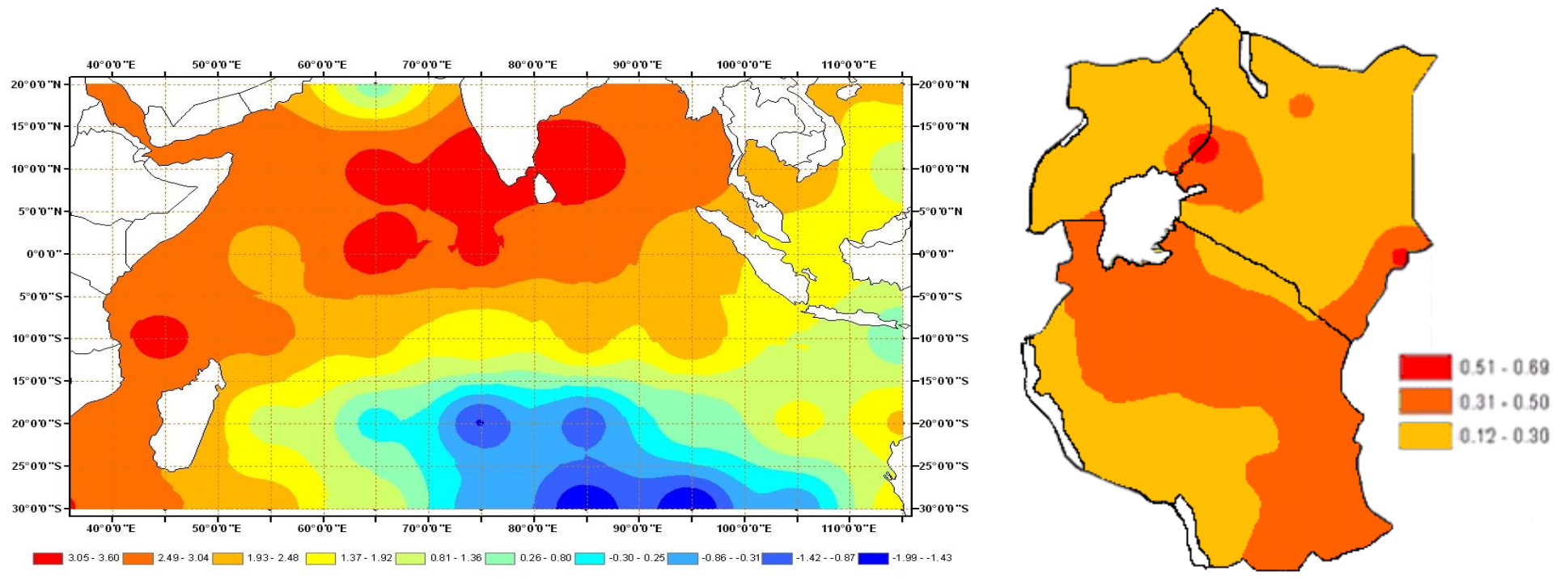

(a) Indian Ocean SST Mode 1

(b) MAM Rainfall Mode 1

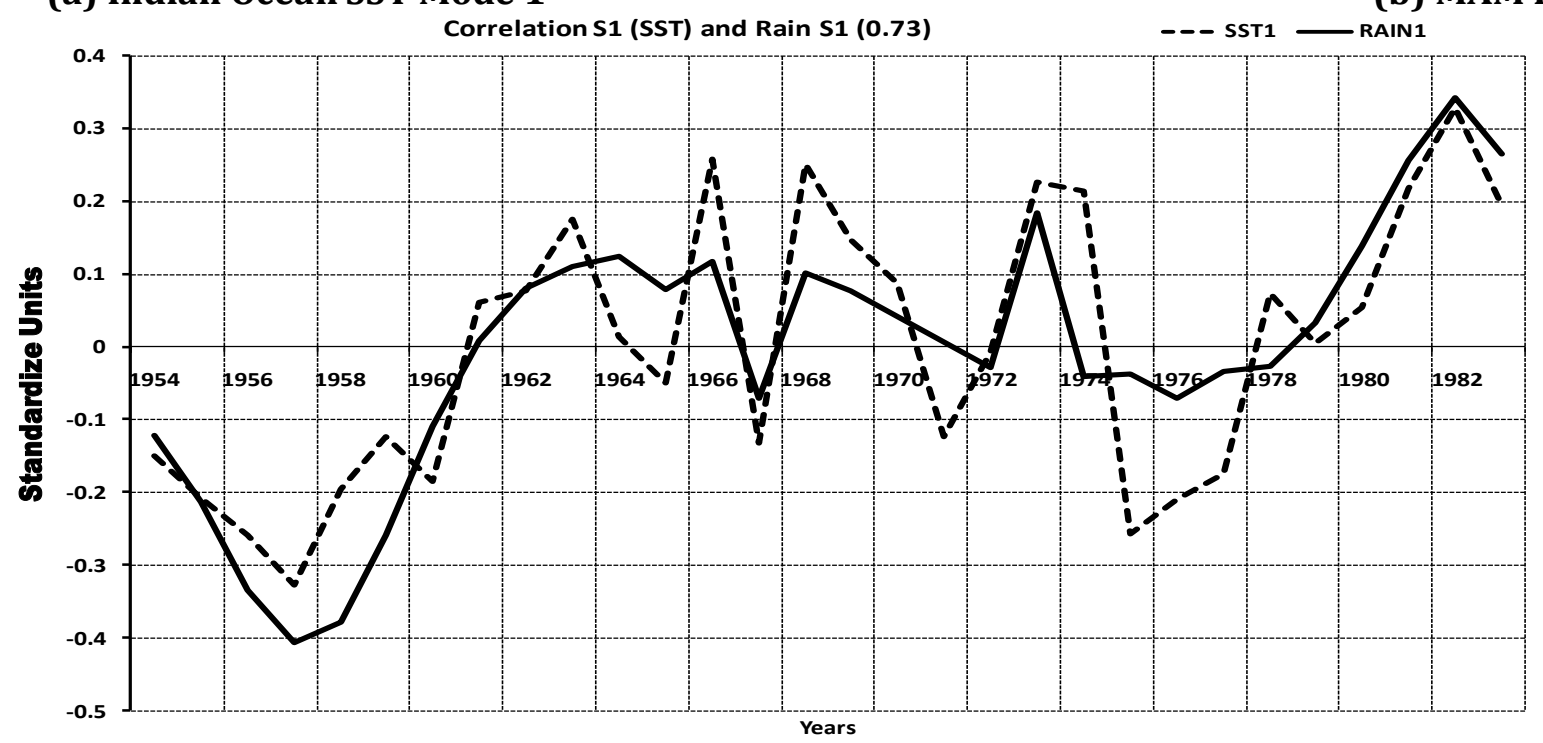

(c) Time series of expansion coefficients (s1) of the first SVD mode Figure 5 
Page 28 of 47

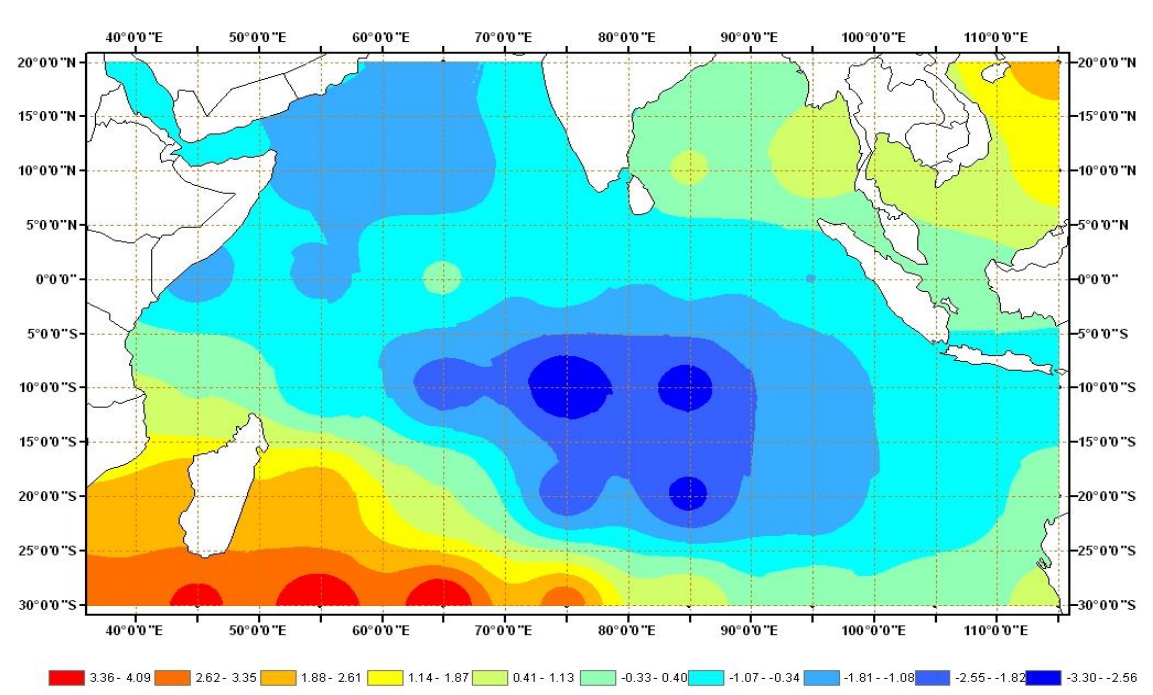

(a) Indian Ocean SST Mode 2

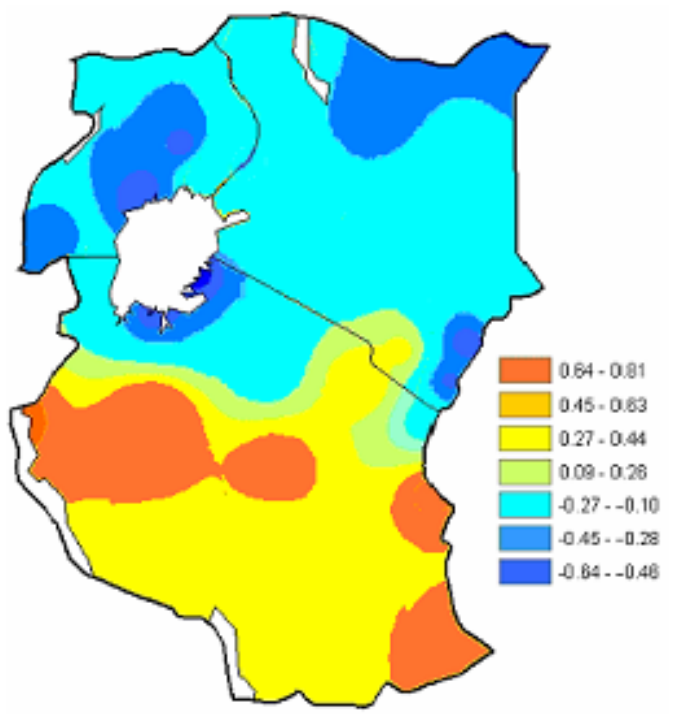

(b) MAM Rainfall Mode 2

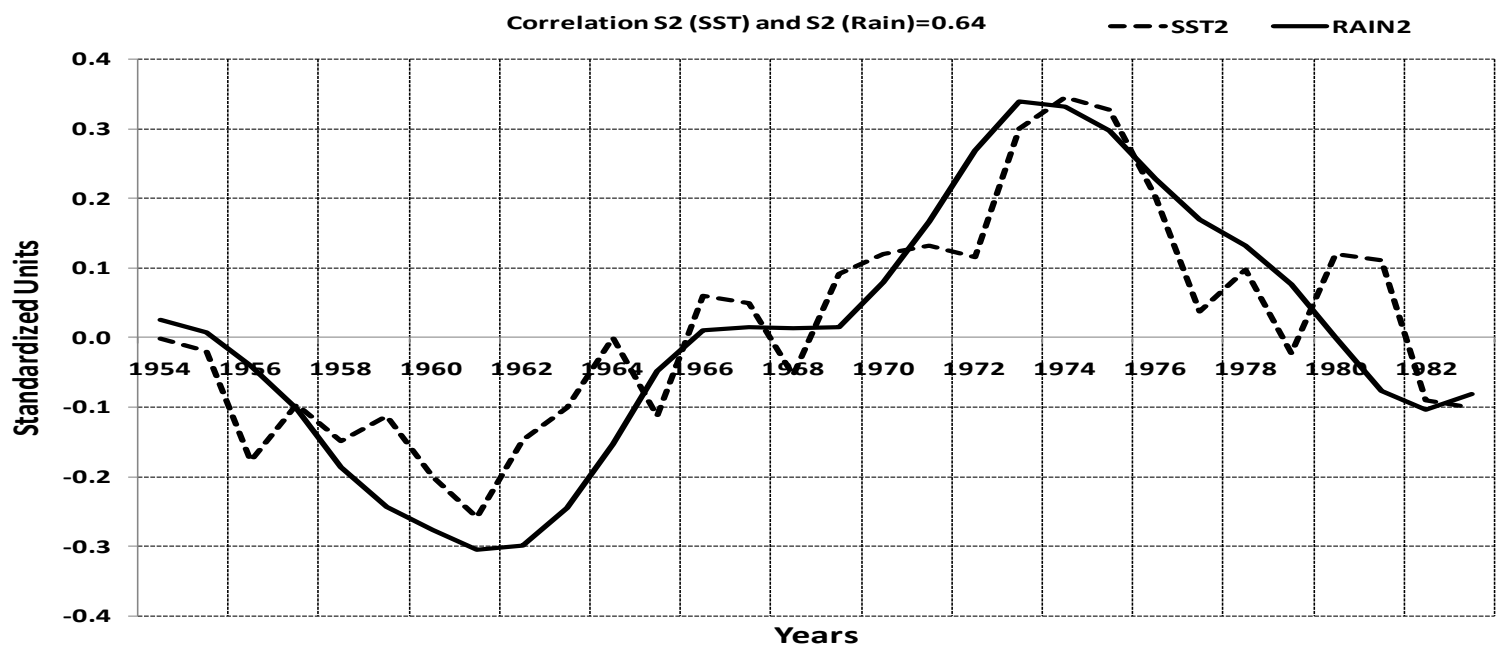

(c) Time series of expansion coefficients (s2) of the second SVD mode

Figure 6 


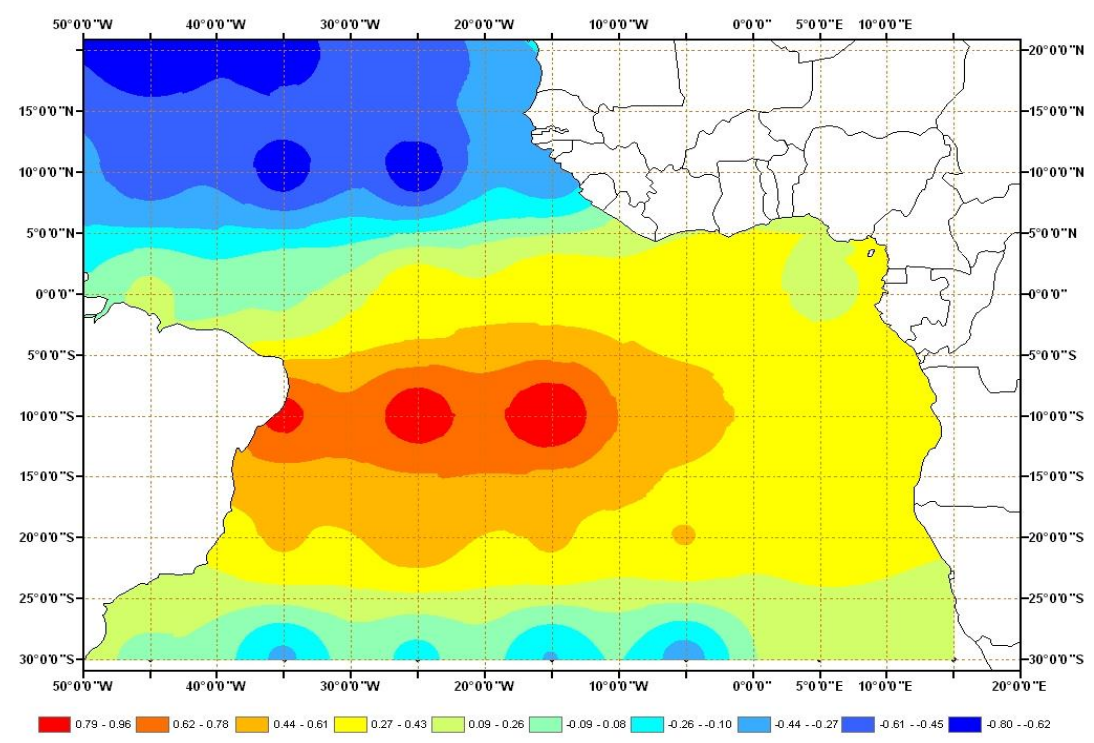

(a) Atlantic Ocean SST Mode 1

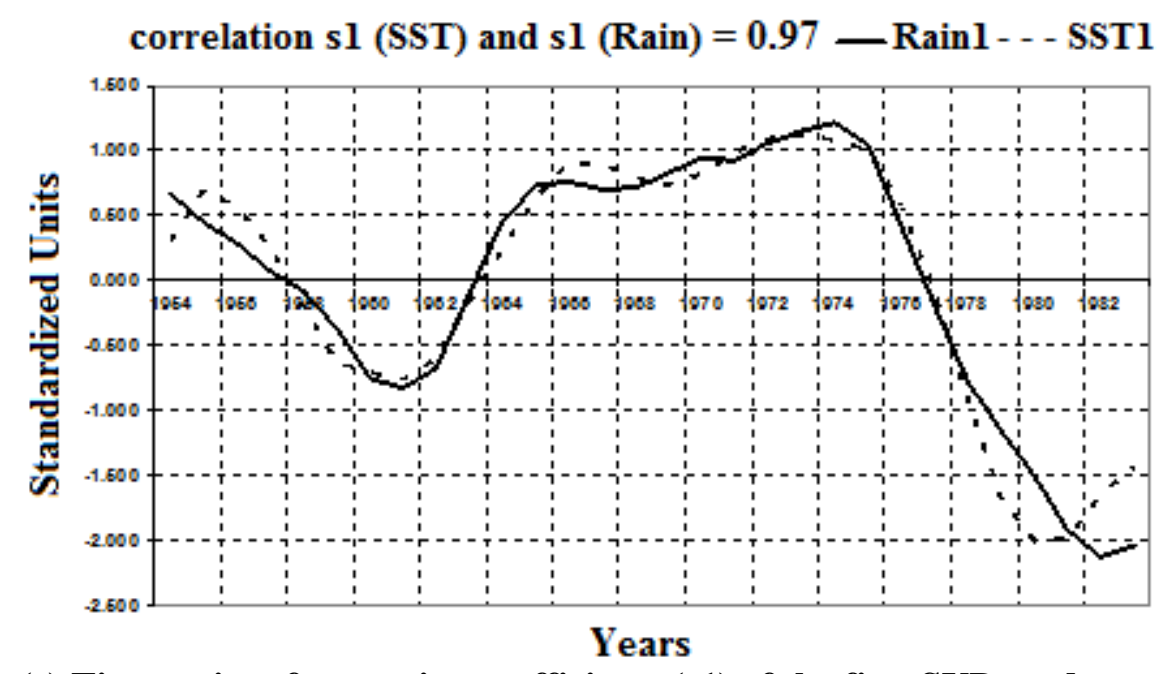

(c) Time series of expansion coefficients (s1) of the first SVD mode Figure 7

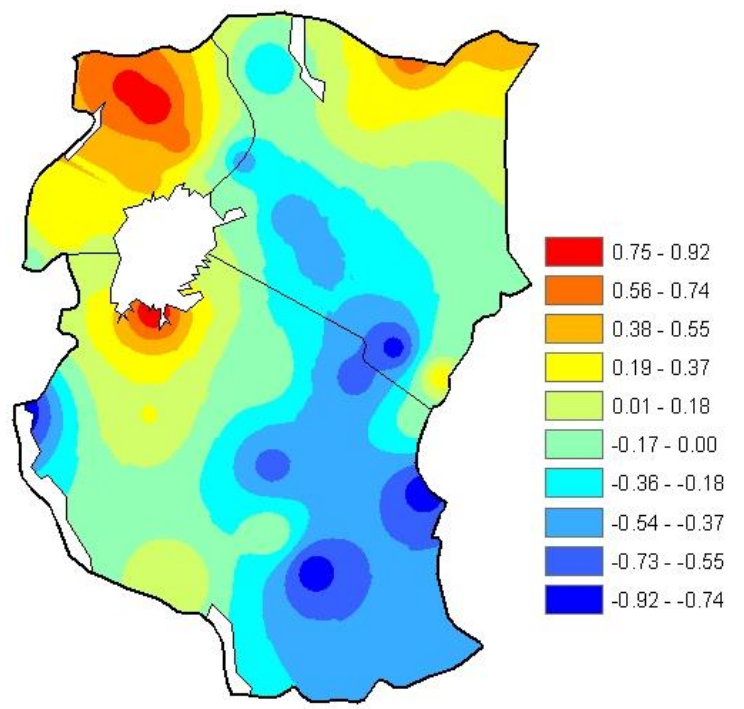

(b) MAM Rainfall Mode 1 


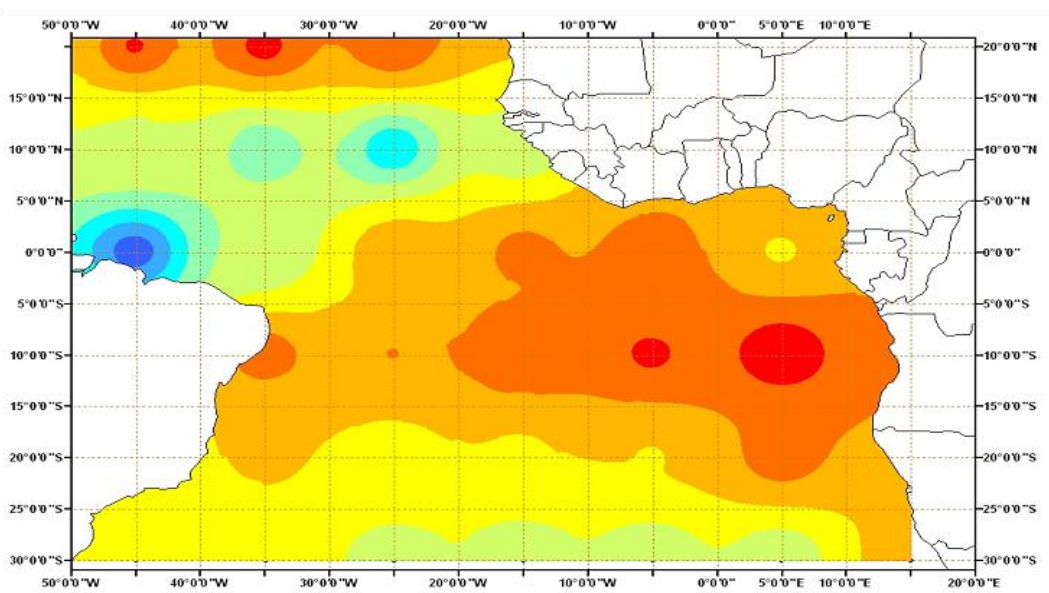

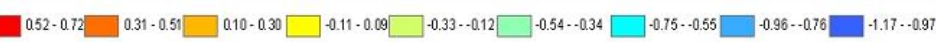

(a) Atlantic Ocean SST Mode 2

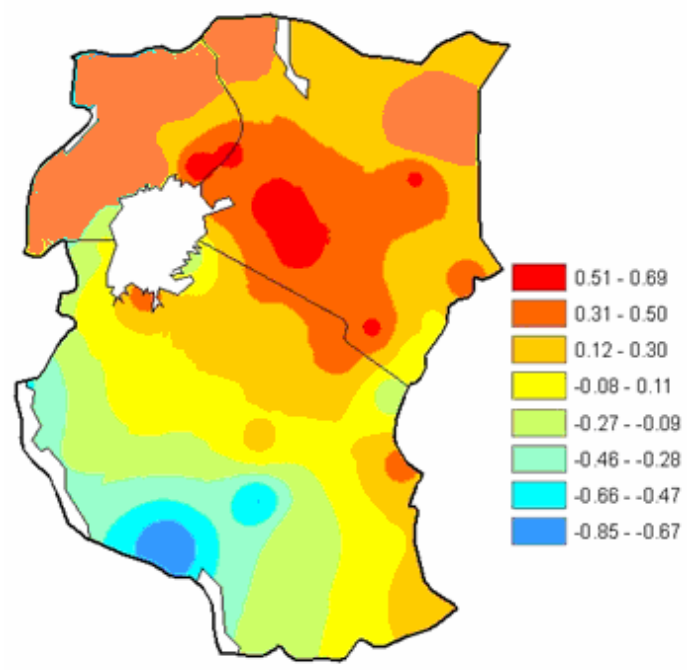

(b) MAM Rainfall Mode 2

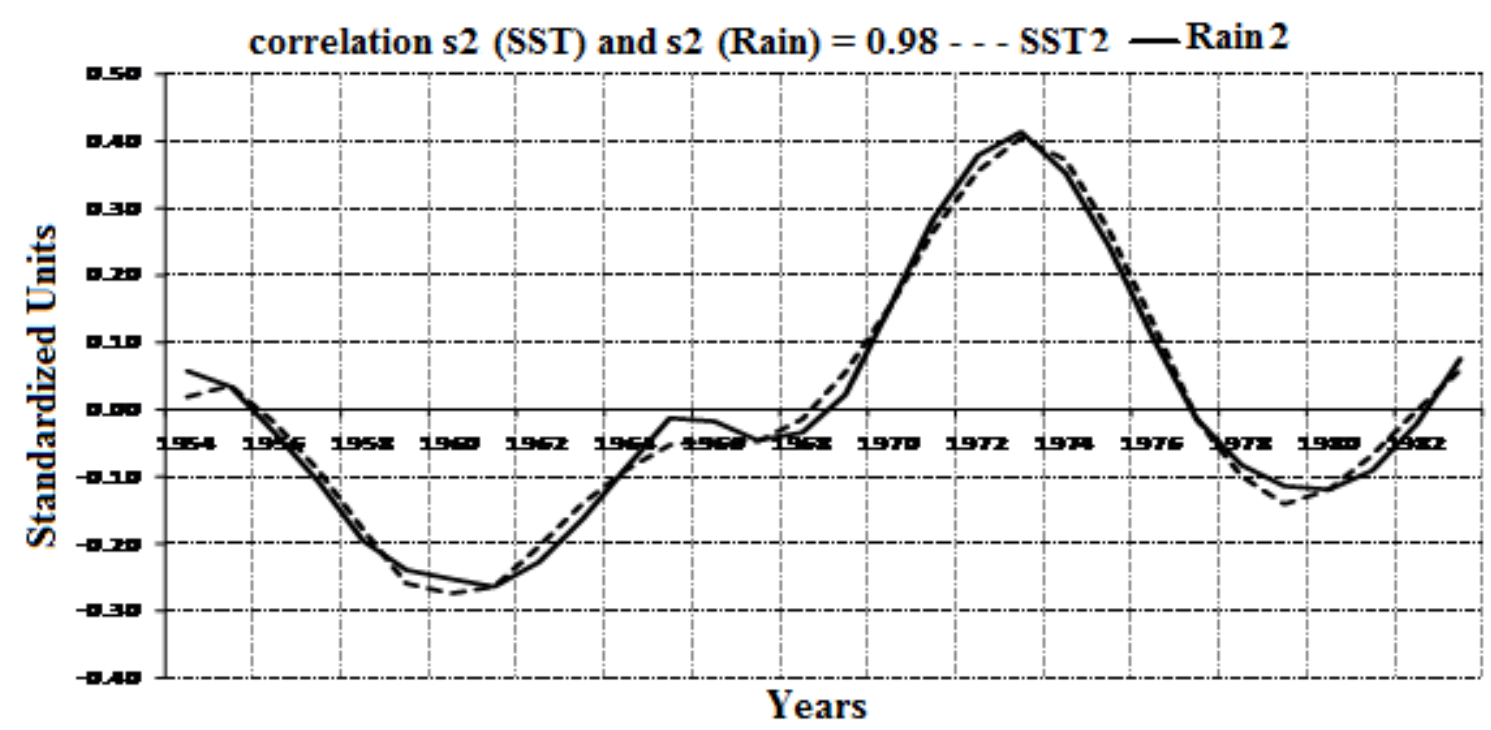

(c) Time series of expansion coefficients (s2) of the second SVD mode

Figure 8 
Page 31 of 47

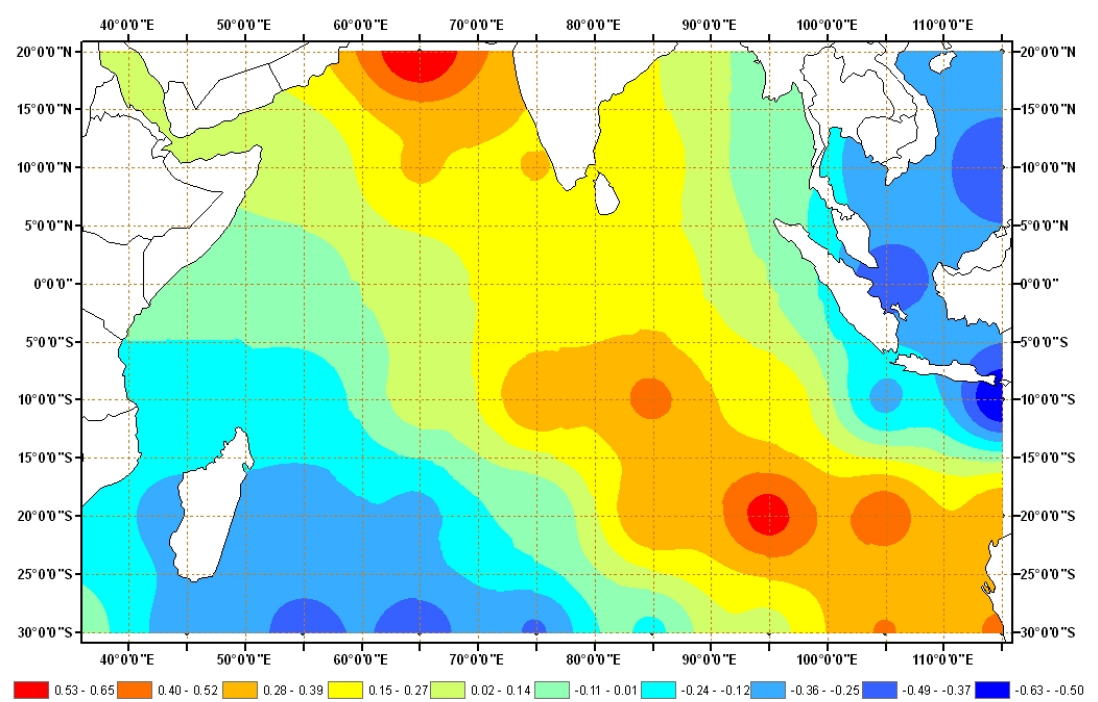

(a) Indian Ocean SST Mode 1

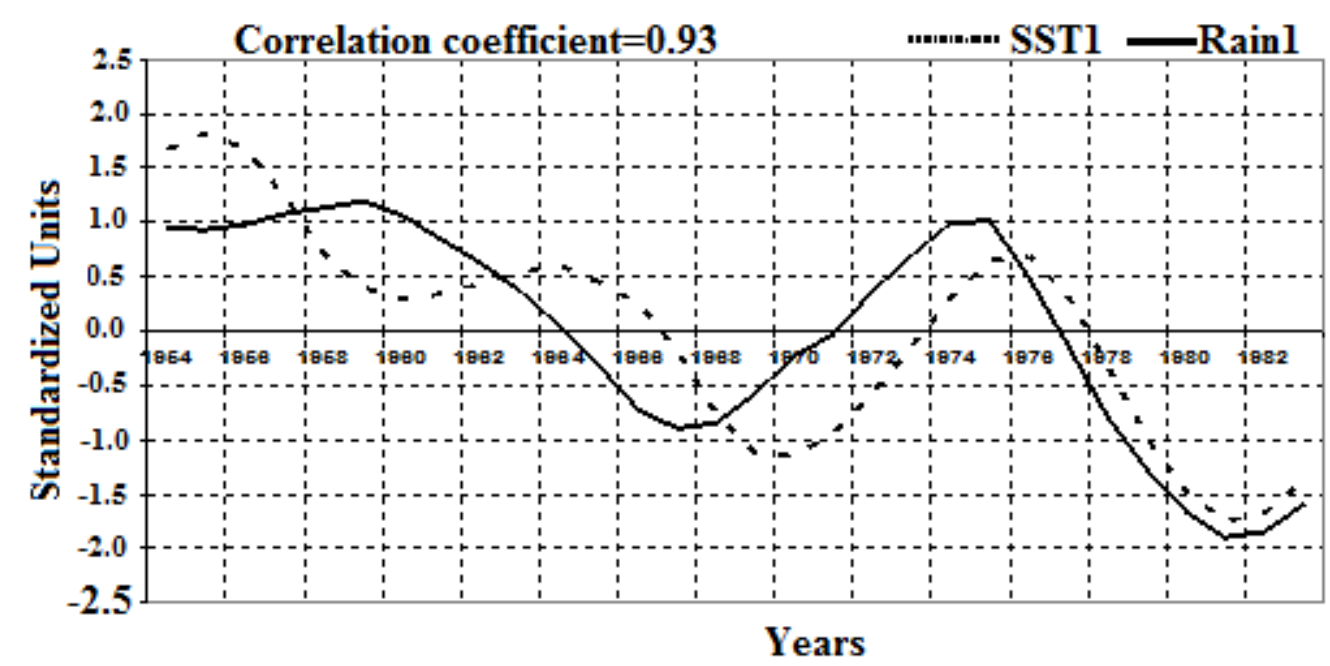

(c) Time series of expansion coefficients (s1) of the first SVD mode

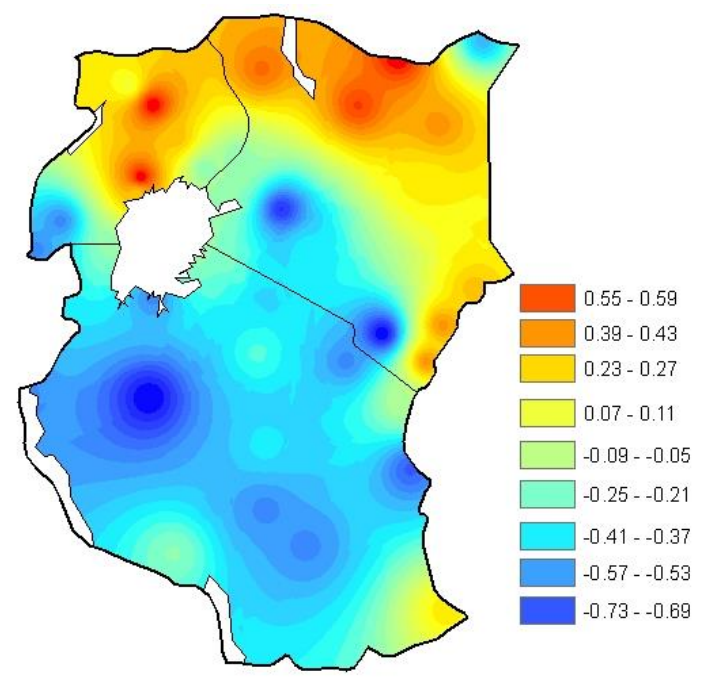

(b) OND Rainfall Mode 1

Figure 9 


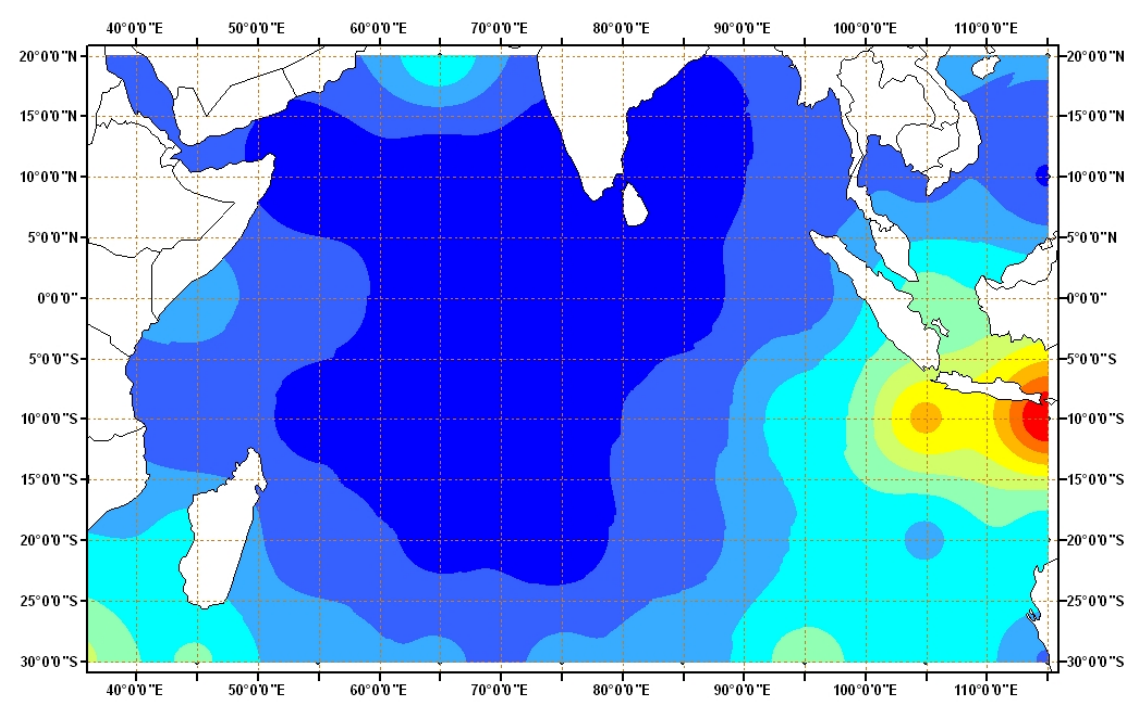

Indian Ocean SST Mode 2

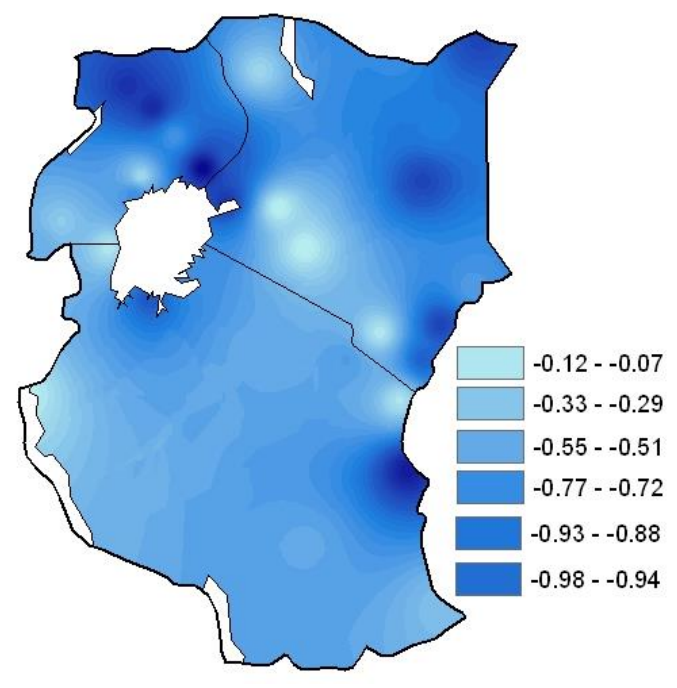

(b) OND Rainfall Mode 2

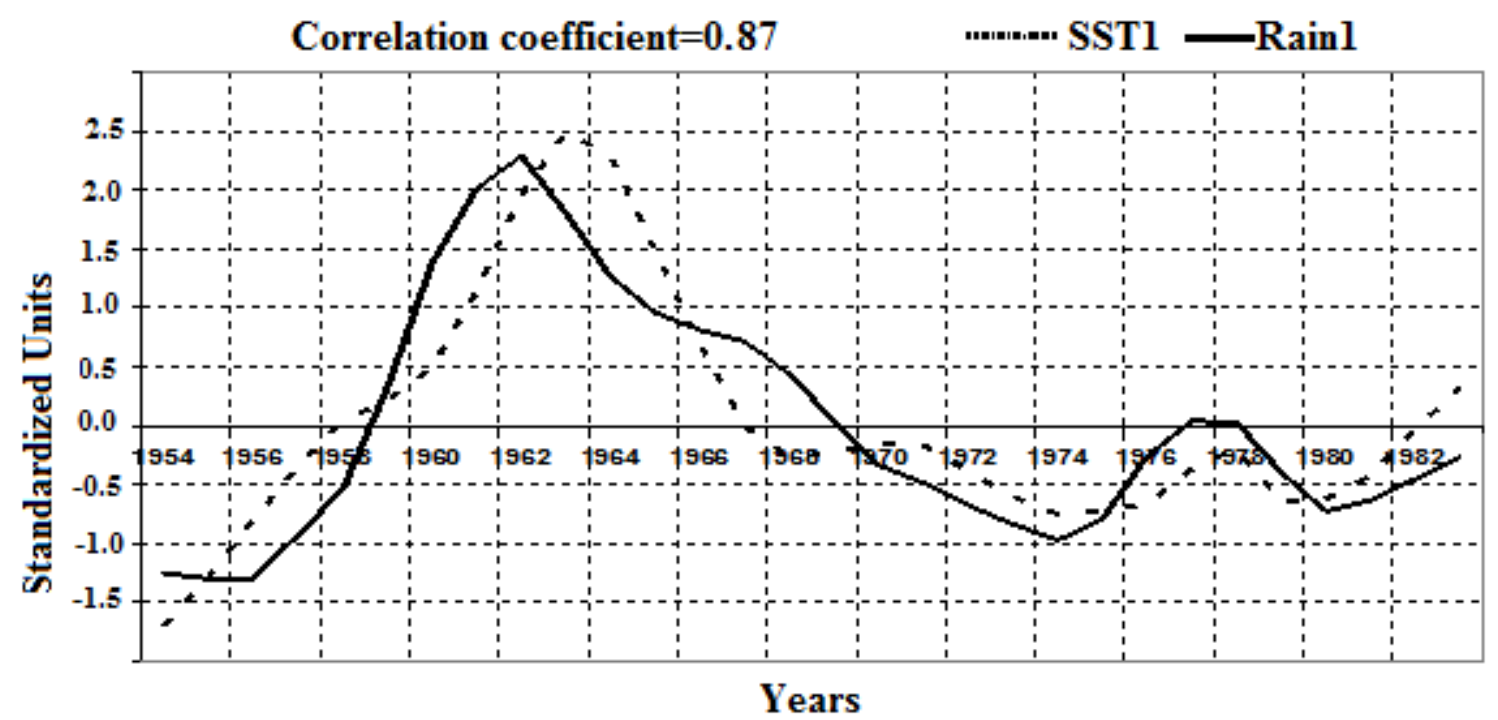

(c) Time series of expansion coefficients (s2) of the second SVD mode Figure 10 


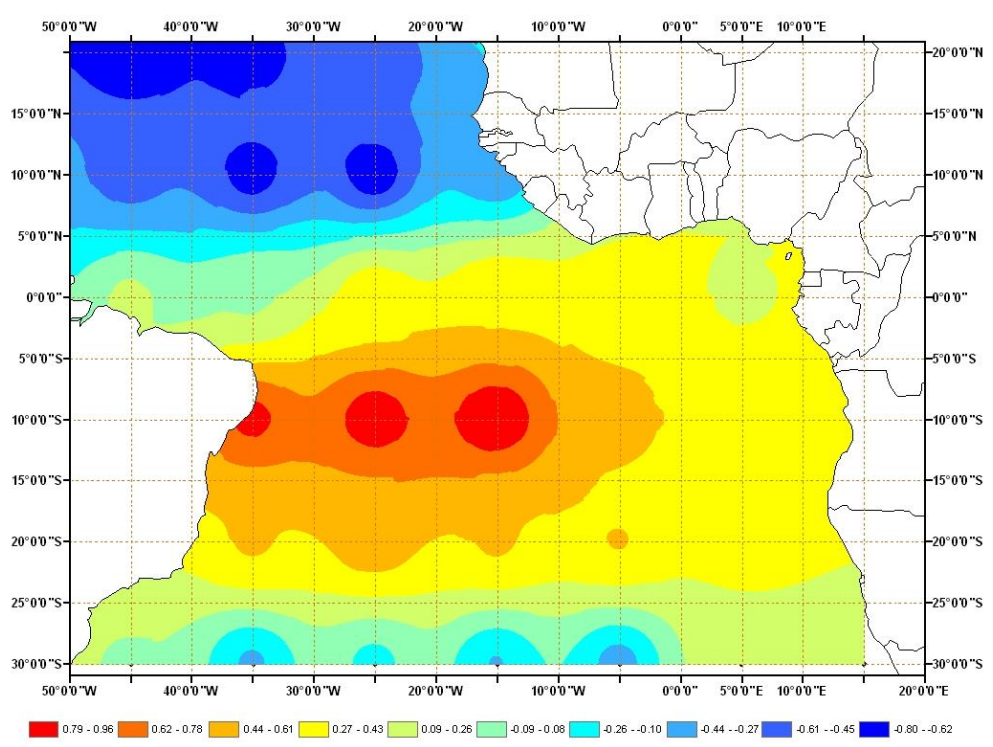

(a) Atlantic Ocean SST Mode 1

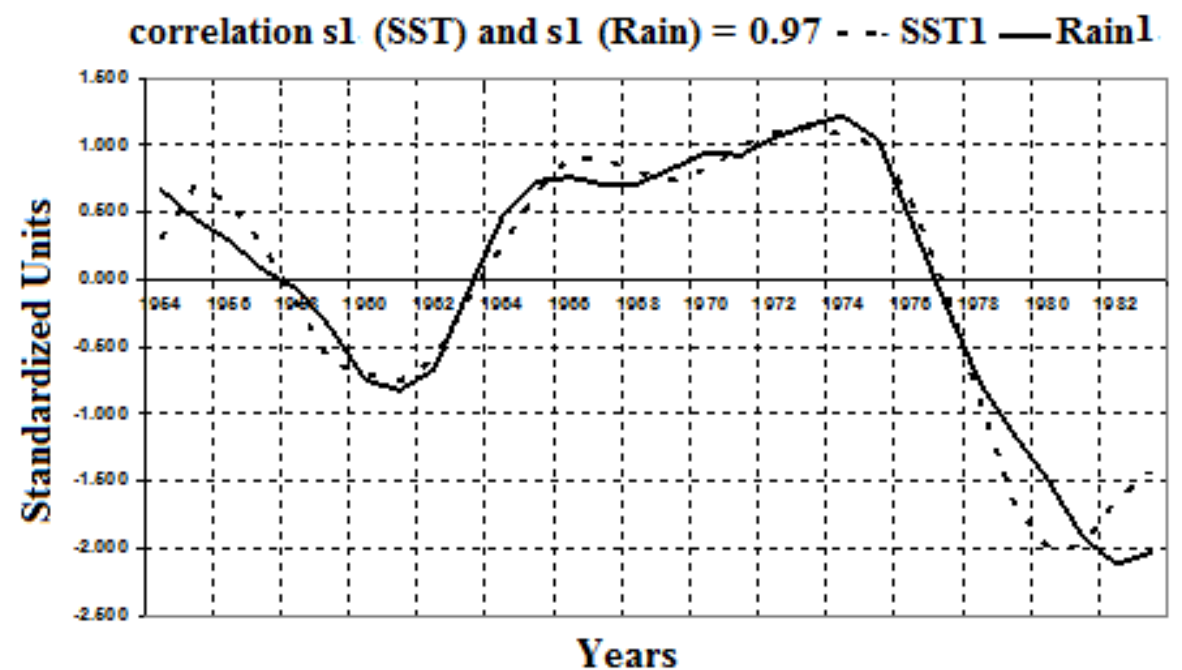

(c) Time series of expansion coefficients (s1) of the first SVD mode Figure 11

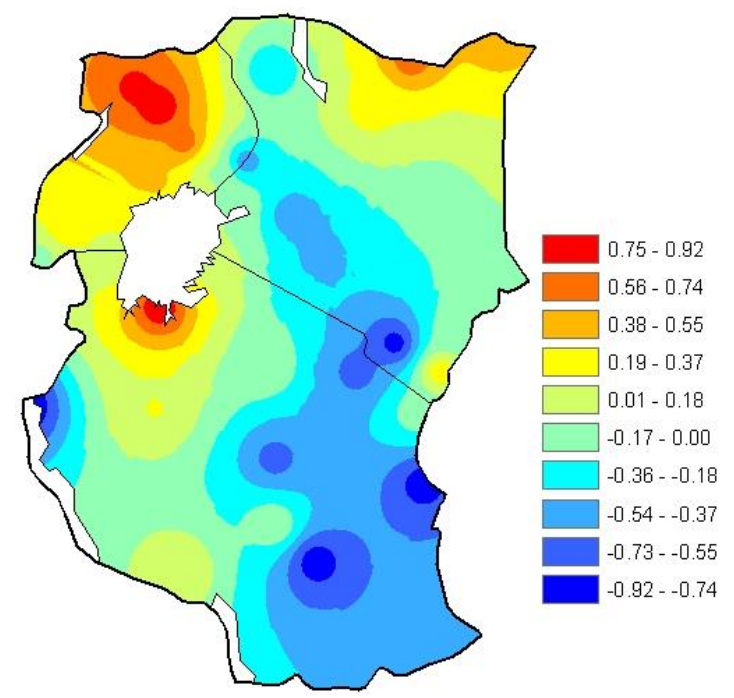

(b) OND Rainfall Mode 1 
Page 34 of 47
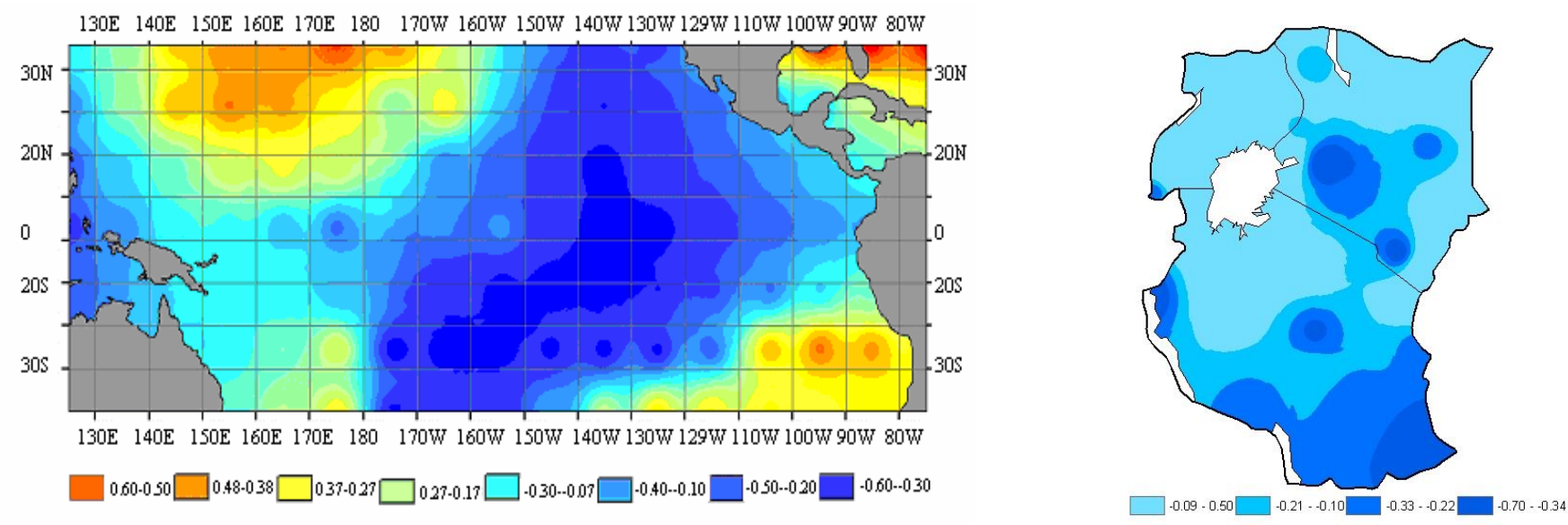

(a) Pacific Ocean SST Mode 2

(b) OND Rainfall Mode 2

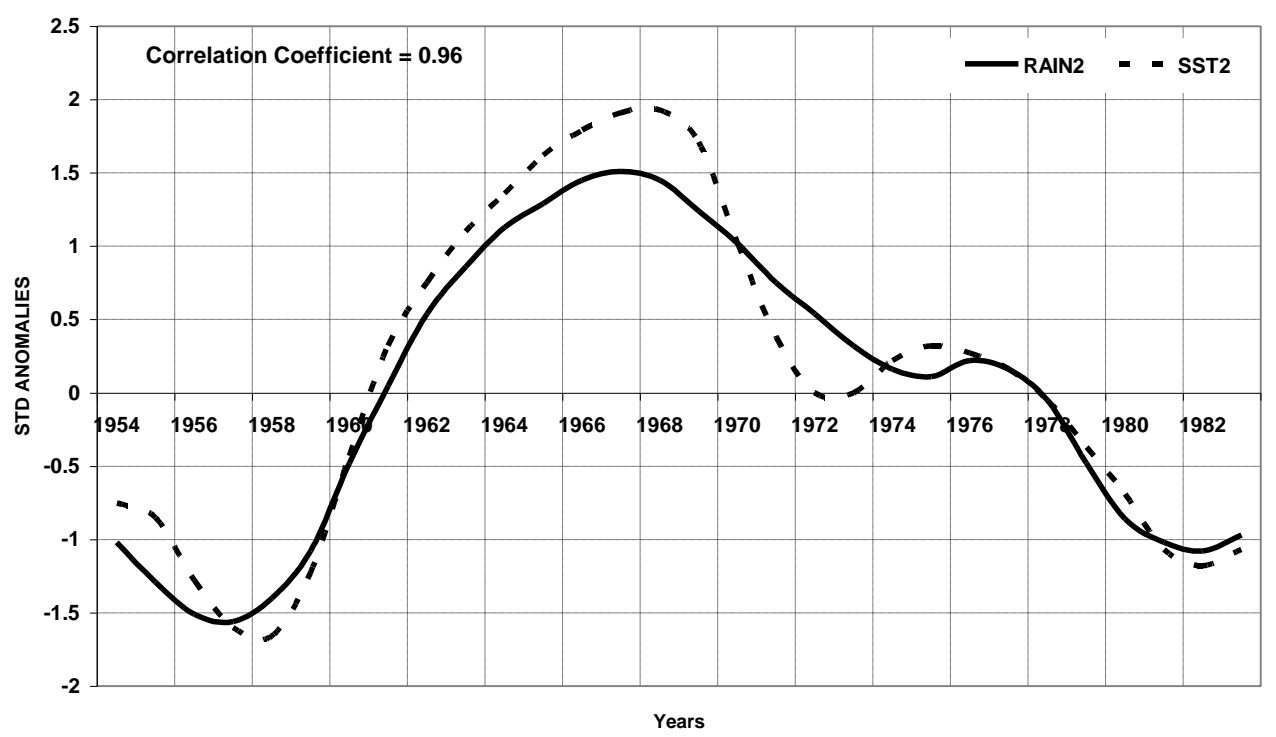

(c) Time series of expansion coefficients (s1) of the first SVD mode

Figure 12 


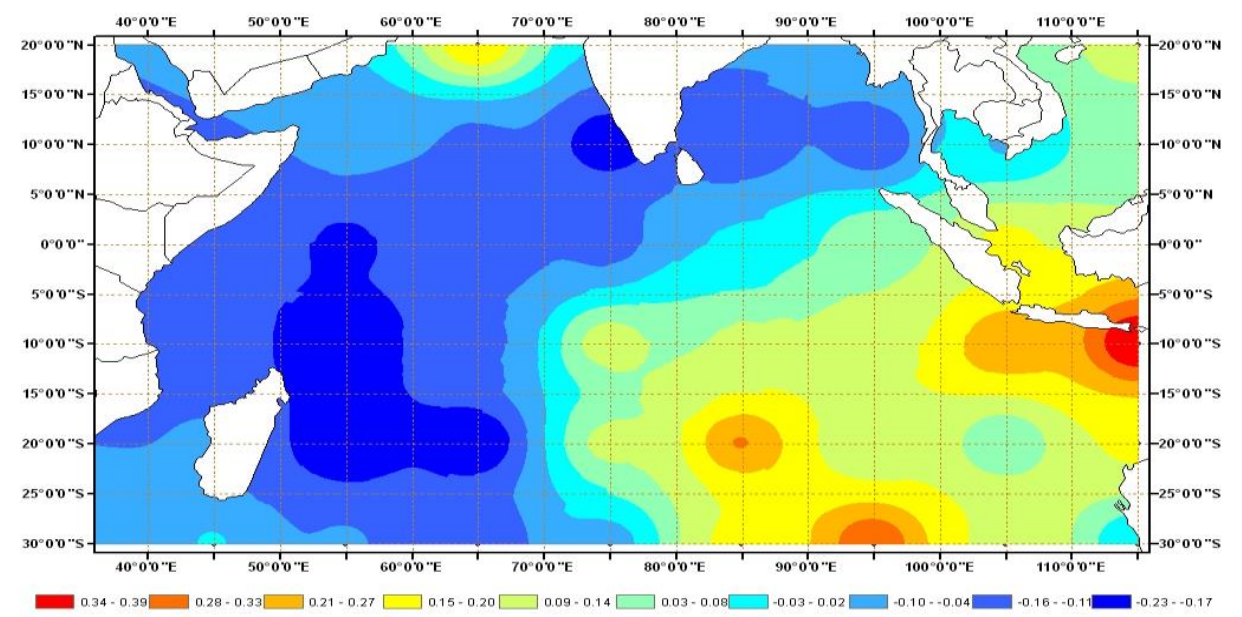

(a) Indian Ocean SST Mode 1

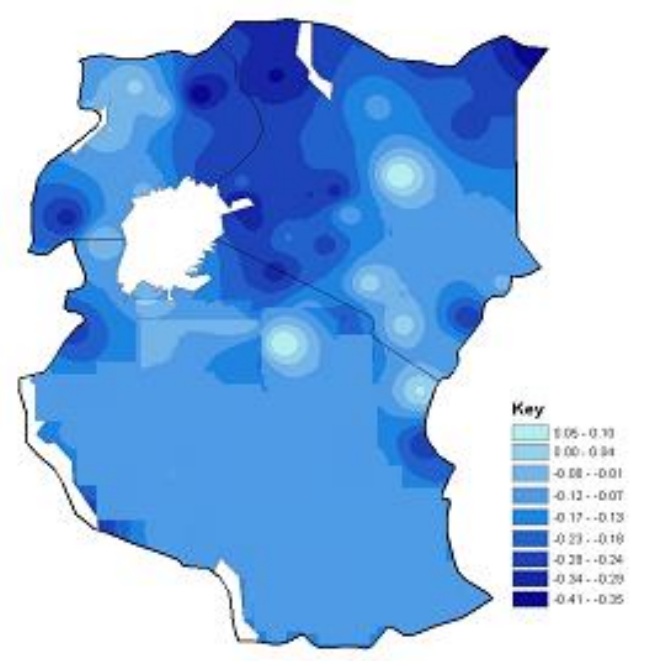

(b) JJA Rainfall Mode 1

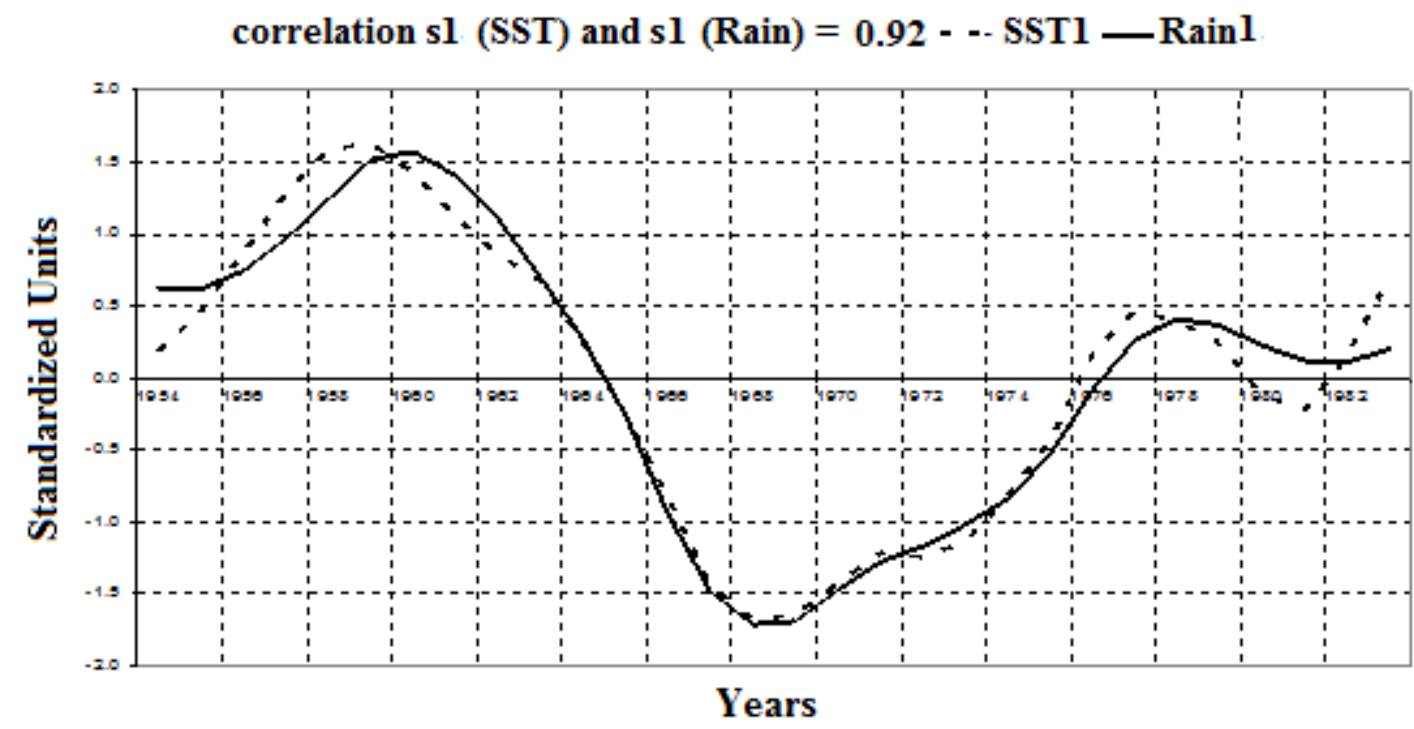

(c) Time series of expansion coefficients (s1) of the first SVD mode

Figure 13 


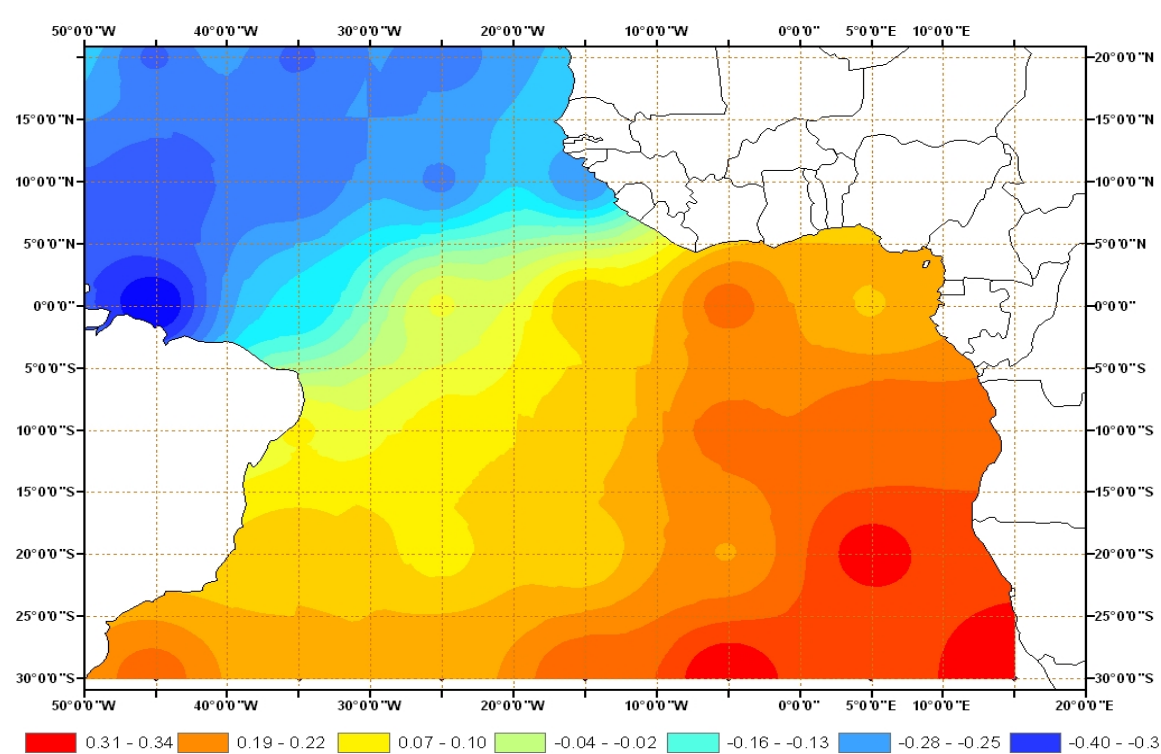

(a) Atlantic Ocean SST Mode 1

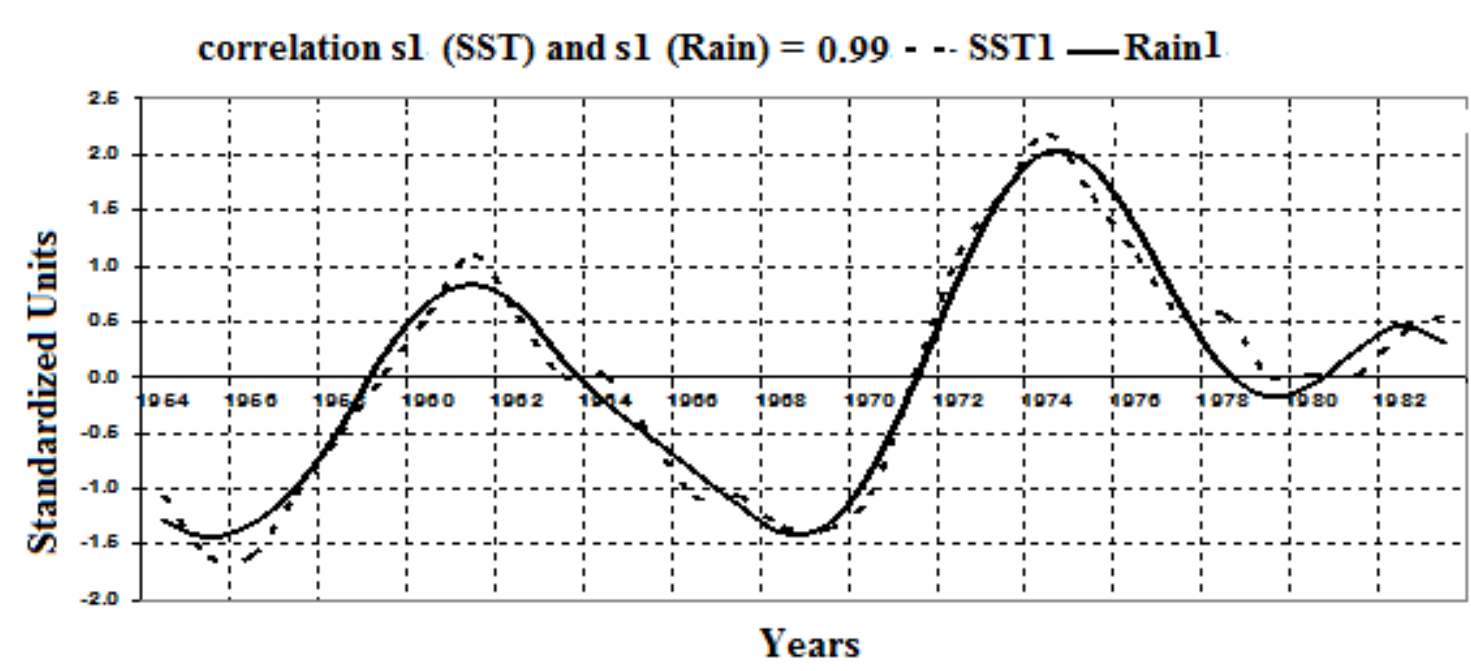

(c) Time series of expansion coefficients (s1) of the first SVD mode

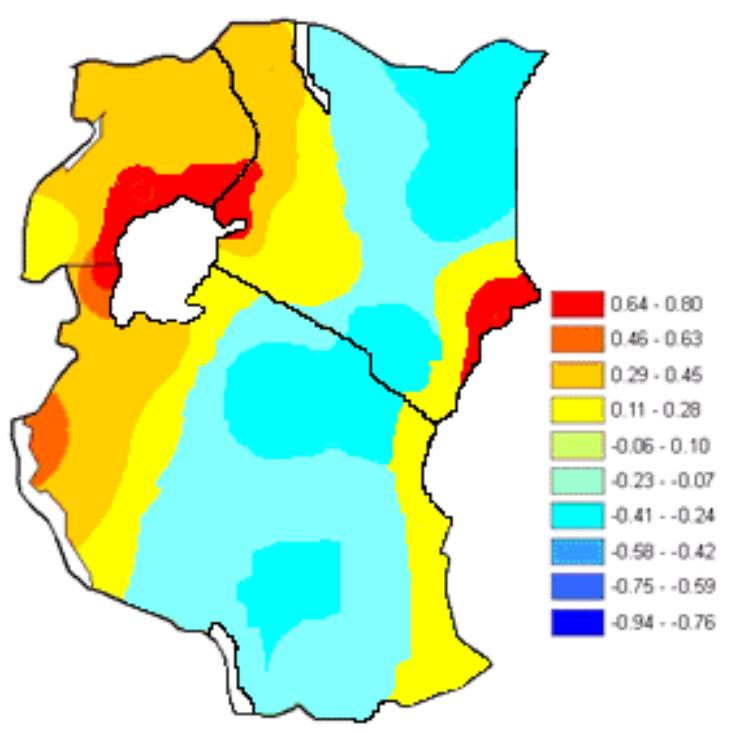

(b) JJA rainfall Mode 1

Figure 14 


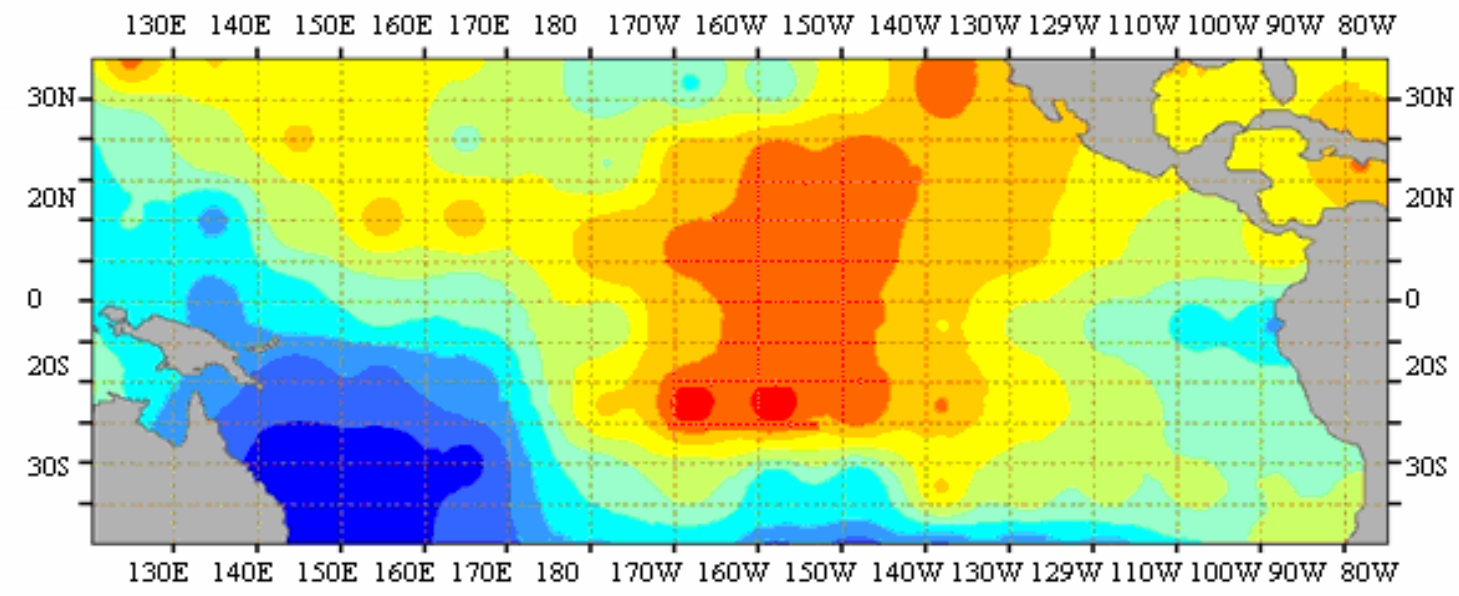

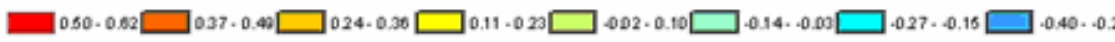

$0.53 \cdot 0.4$

(a) Pacific SST Mode 2

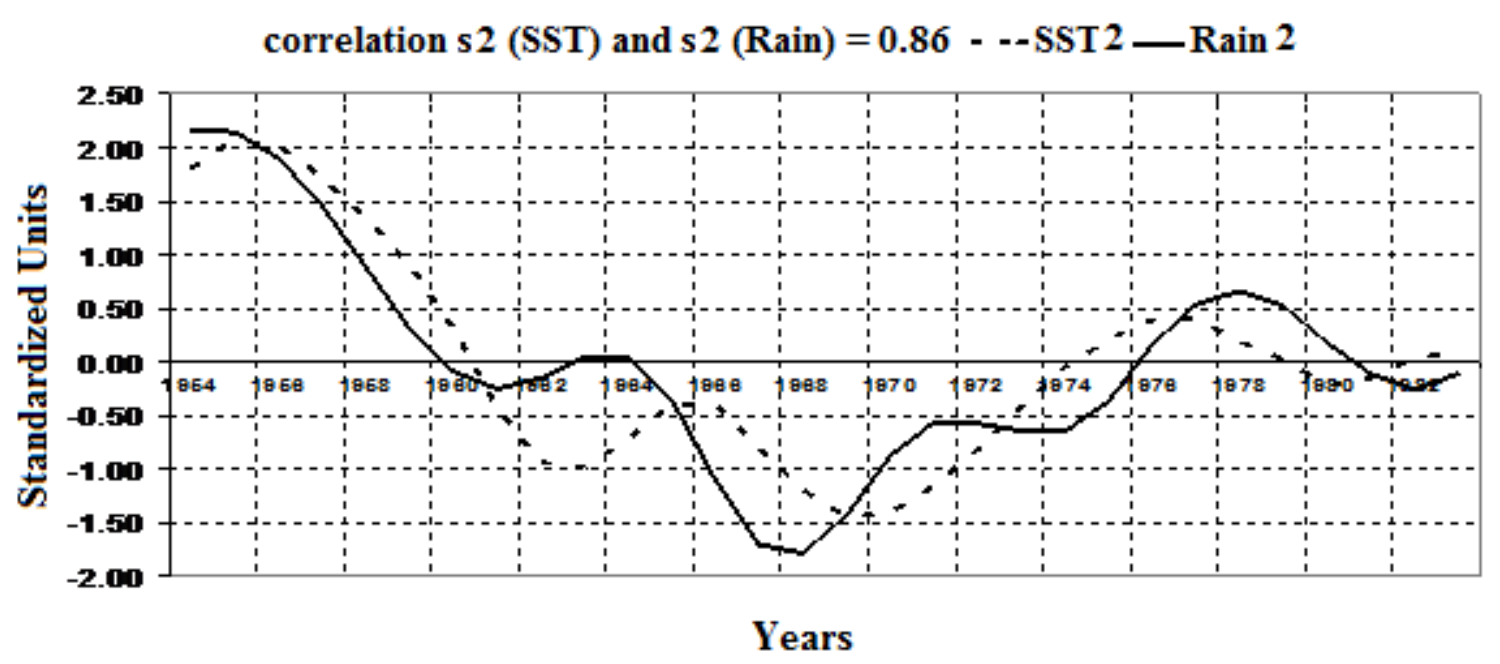

(c) Time series of expansion coefficients (s2) of the second SVD mode

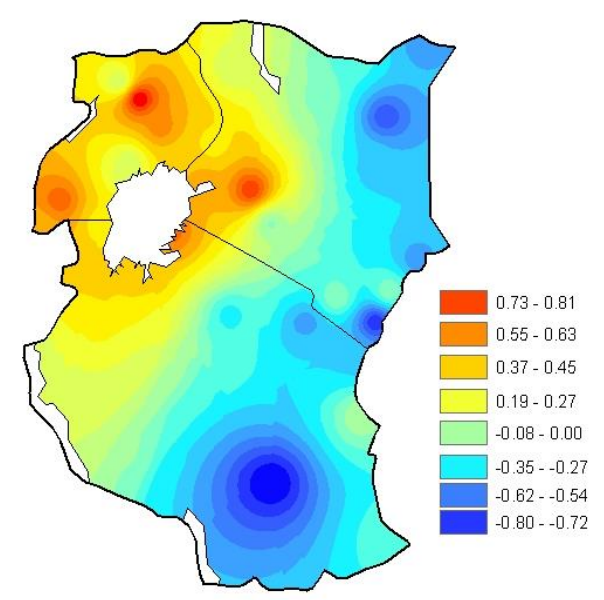

(b) JJA rainfall Mode 2

Figure 15 


\section{References}

Anyah, R.O., and W. Qiu, 2012: Characteristic 20th and 21st century precipitation and temperature patterns and changes over the Greater Horn of Africa. Int. J. Climatol. 32: 347-363.

Ashok, K., Behera, S.K., Rao, S.A., Weng, H. , and T. Yamagata, 2007: El Niño Modoki and its possible teleconnection, J. Geophys. Res., 112, C11007, doi: 10.1029/2006JC003798.

Ashok, K., Iizuka, S. , Rao, S.A., Saji, N.H., and W.J. Lee, 2009: Processes and boreal summer impacts of the 2004 El Niño Modoki: An AGCM study, Geophys. Res. Lett., 36, L04703, doi: 10.1029/2008GL036313.

Barnett, T.P., and R. Preisendorfer, 1987: Origins and levels of monthly and seasonal forecasts skill for United States surface air temperatures determined by Canonical Correlation Analysis. Mon. Wea. Rev., 115, 1825 - 1850.

Barnston, A.G., and T.M. Smith, 1996: Specification and prediction of global surface temperature and precipitation from global SST using CCA. J. Climate, 9, 2660-2697.

Barnston A. G., Thiao W. and V. Kumar, 1996: Long-lead forecasts of seasonal precipitation in Africa using CCA. Weather and Forecasting 11: 506-520.

Bark, D.L. 1978: History of American Droughts. North American Droughts. A Selected Symposia Series. Westview Press, Boulder Colorado, N.J. Rosenberg, Ed., pp 9-23.

Barry, R.G., and R.J. Chorley, 1968: Atmosphere, Weather and Climate, 4th Edition, Methuen, London and New York, 407pp.

Basalirwa, C.P.K 1991: Raingauge network designs for Uganda, Ph.D Thesis, University of Nairobi, Kenya.

Basalirwa, C.P.K. 1995. Delineation of Uganda into climatological rainfall zones using the method of principal component analysis. International journal of climatology, 15, 1161-1177

Becker, M., Llovel, W., Cayenave, A., Günter, A and J-F. Crétaux, 2010: Recent hydrological behavior of the East African great lakes region inferred from GRACE, satellite altimetry and rainfall observations, C. R. Geoscience 342, 223-233, doi:10.1016/j.crte.2009.12.010.Behera, S.K, Luo, J. J., Masson, S., Delecluse, P., Gualdi, S., and A. Navarra, 2005: Paramount Impact of the Indian Ocean Dipole on the East African short Rains: ACGCM study. J. Climate, 18, 41-54.

Behera SK, Luo JJ, Masson S, Delecluse P, Gualdi S, Navarra A., 2005. Paramount Impact of the Indian Ocean Dipole on the East African short Rains: ACGCM study. Journal of Climate 18: 41-54. 
Bjerkness, J., 1969: Atmospheric teleconnections from the equatorial Pacific. Mon Wea Rev 97, 163-172.

Black, E, Slingo, J., and K.R. Sperber, 2003: An observational study of the relationship between excessively strong short rains in the coastal East Africa and Indian Ocean SST., Mon Wea. Rev. 131, 74-94.

Black, E., 2004: The relationship between Indian Ocean sea-surface temperature and East African rainfall, Phil. Trans. R. Soc. A 2005 363, 43-47, doi:10.1098/rsta.2004.1474.

Bloomfield, P., 1976: Fourier analysis of time series: An introduction: John Wiley and sons, p.256-.799 [Smoothed periodogram method of spectral analysis].

Bowden, J., Semazzi, F.H.M., Anyah, R., and C. Schreck., 2004: Intraseasonal to Decadal Variability of the Greater Horn of Africa, North Carolina State University, Raleigh, North Carolina.

Bretherton, C.S., Smith, C., and J. M. Wallace, 1992: An intercomparison of methods for finding coupled patterns in climate data. J. Clim., 5:541-560.

Burroughs ,W.J., 1999: The climate revealed., Mitchell Beazley, An Imprint of Octopus Publishing Group Ltd, 2-4 Heron Quays, London; 129pp.

Cai, W., and T. Cowan, 2007: Trends in the southern Hemisphere circulation in IPCC AR4 models over 1950-99: Ozone depletion versus greenhouse forcing. J. Climate, 20, No.4, 681-693.

Cattel, R.B., 1966: The Scree test for the number of factors. Multivar. Behav. Res., 1, 245259.

Clark, C. O., Webster, P. J., and J.E. Cole, 2003: Interdecadal variability of the relationship between the Indian Ocean Zonal Mode and East African coastal rainfall anomalies. J. Climate, 16, 548-554.

CLIVAR VACS, 2007: Decadal variability issues in Africa.

Chu, P. C., 1989: Relationship between thermally forced surface wind and sea surface temperature gradient. J. Pure and Applied Geophysics, 130, No. 1,31-45.

Cohen, S.J., 1983: Classification for $500 \mathrm{mb}$ Height Anomalies using obliquely rotated principal components. J. of App.lied Meteor. vol.22, No.12, 1975-1988.

Forootan, E., Awange, J.L., Kusche, J., Heck, B., and A. Eicker, 2012: Independent patterns of water mass anomalies over Australia from satellite data and models. Journal of Remote Sensing of Environment, doi:0.1016/j.rse.2012.05.023. 
Garci'a-Garci'a, D., Ummenhofer, C.C., and V. Zlotnicki, 2011: Australian water mass variations from GRACE data linked to Indo-Pacific climate variability. Remote Sensing of Environment 115, 2175-2183, doi:10.1016/j.rse.2011.04.007.

Gissila, T., Black E., Grimes, D.I.F., and J.M. Slingo, 2004: Seasonal forecasting of Ethiopian summer rains. International Journal of Climatology, 24, 1345-1358.

Goddard, L. and N.E. Graham, 1999: Importance of the Indian Ocean for simulating rainfall anomalies over eastern and southern Africa. J. Geophysical Research, 104, No. D16, 19099 - 19116.

Goldenberg, S.B., Landsea, C.W., Mestas-Nuñez, A.M., and W.M. Gray, 2001: The recent increase in Atlantic hurricane activity: Causes and implications. Science, 293, 474-479.

Gottman J. M., 1981: Time-series Analysis. A Comprehensive Introduction for Social Scientists, Pp. 400-430, Cambridge University Press: Cambridge.

Gregory, S., 1975: On the delimitation of Regional patterns of recent climatic fluctuations. Mon. Wea. Rev., 30,276-287.

Harrison, D.E., and M. Carson, 2007: Is the world ocean warming? Upper ocean temperature trends: 1950-2000. J. Phys. Oceanogr., 37, No. 2, 174-187.Hastenrath, S. and Polzin, D., 2003: Circulation mechanisms of climate anomalies in the equatorial Indian Ocean. Meteorol. Z., 12, 81-93.

Huang, B., and J. Shukla, 2007: Mechanisms for the Interannual Variability in the Tropical Indian Ocean. Part I: The Role of Remote Forcing from the Tropical Pacific, J. Climate, 20, 2917-2936

Hye-Mi Kim, Webster, P.J., and J.A. Curry, 2009: Impact of Shifting Patterns of Pacific Ocean Warming on North Atlantic Tropical, Science 3 July 2009: Vol. 325. no. 5936,. 77 - 80.

ICPAC, 1999: Homogeneous Climatological Zoning DMC Lecture Notes, chapter 3, 29 - 43.

Ihara, C., Kushnir, Y., and M.A. Cane, 2008: Warming Trend of the Indian Ocean SST and Indian Ocean Dipole from 1880 to 2004, J. Climate, 21, 2035-2046.

Indeje, M., 2000: Prediction and numerical simulation of regional climate of equatorial eastern Africa. PhD Thesis, North Carolina State University, U.S.A. pp 327

Indeje, M., Semazzi, F.H.M., and L.J. Ogallo, 2000: ENSO signals in East African rainfall seasons. Int. J. Climatology, 20, 19-46.

ICPAC, 1999: Homogeneous Climatological Zoning DMC Lecture Notes, chapter 3, 29 - 43

IPCC, 2007: Summary for Policymakers. In: Climate Change 2007: The Physical Science Basis. Contribution of Working Group I to the Fourth Assessment Report (AR4) of the Intergovernmental Panel on Climate Change [Solomon, S., D. Qin, M. Manning, Z. Chen, M. Marquis, K.B. Averyt, M.Tignor and H.L. Miller (eds.)]. Cambridge University Press, Cambridge, United Kingdom and New York, NY, USA 
IPCC, 2007: Forth Assessment Report, Climate Change 2007 (AR4), Working Group II summary for policy makers.

Jenkins, G.M. and Watts, D.G., 1968: Spectral Analysis and Its Applications. Holden-Day, California, U.S.A

Kaiser, H.F. 1958: The Varimax Criterion for Analytic Rotation in Factor Analysis. Psych., 23, pp. 187-200.

Kaiser, H.F. 1959: Computer program for varimax rotation in factor analysis, Educ. Physchol. Meas., 19, 1413-1420.

Kanamitsu, M., Ebisuki, W. , Wollen, J., Yang, S. K , Hnilo, J. J., Fiorino M., and G. L. Potter, 2002: NCEP -DOE AMIP- II reanalysis ,R-2, Bull. Amer. Meteor. Soc., 83, No. 11, 16311643.

Keenlyside, N., Latif, M., Junclaus, J., Kornblueh, L. and E. Roeckner, 2008: Advancing decadal climate scale prediction in the North Atlantic. Nature, 453, 84-88.

Keller, K., Deutssch, C.., Hall, M.G., and D.F. Bradford, 2007: Early detection of changes in the north Atlantic meridional overturning circulation: Implications for the design of ocean observation systems. J. Climate, 20 No. 2, 145-157.

Knutson, T.R. and R. E. Tuleya, 2004: Impact of CO2-induced warming on simulated hurricane intensity and precipitation: Sensitivity to the choice of climate model and convective parameterization. J. Clim. 17, 3477 - 3495.

Korecha, D., and A.G. Barnston, 2007: Predictability of June to September rainfall in Ethiopia. Monthly weather Review, 135, 628-650.

Koopmans. L. H., 1995: The Spectral Analysis of Time Series (Probability and Mathematical Statistics), Volume 22, 2nd. edition

Kug, J.S., Kirtman, B. P., and I.S. Kang, 2006: Interactive Feedback between ENSO and the Indian Ocean in an Interactive Ensemble Coupled Model. J. Climate, 19, 6371-6381

Kug, J.S., and I.S. Kang, 2006: Interactive feedback between the Indian Ocean and ENSO. J. Climate, 19, 1784-1801.

Lee, T.C.K., Zwiers, F., Zhang, X., and M. Tsao, 2006: Evidence of decadal climate prediction skill resulting from changes in anthropogenic forcing. J. Climate, 19, 5305-5318.

Li, S., Robinson, W.A., Hoerling, M.P. and K.M. Weickmann, 2007: Dynamics of the extratropical response to a tropical Atlantic SST anomaly. J. Climate, 20, No.3, 560-574.

Lindzen, R. S. and S. Nigam, 1987: On the role of sea surface temperature gradients in forcing low-level winds and convergence in the tropics. J. Atmos. Sci., 44, 2418-2436.

L'H^ote, Y., Mah'e, G., Som'e, B., and J. P. Triboulet, 2002: Analysis of a Sahelian annual rainfall index from 1896 to 2000; the drought continues. Hydrological Sciences JournalJournal Des Sciences Hydrologiques 47: 563-572. 
Mann, E.M., and J. Park, 1996: Joint Spatiotemporal Modes of surface Temperature and Sea Level Pressure Variability in the Northern during the Last Century. Journal of Climate, 9, 2137-2162.

Meehl, G.A., and K.A. Hibbard, 2007: A strategy for climate change stabilization experiments with AOGCMs and ESMs. WCRP Informal Report No. 3/2007, ICPO Publication No. 112, IGBP Report No.57, World Climate Research Programme: Geneva, 35 pp..

Meehl, G.A., Goddard, L., Murphy, J., Stouffer, , Boer, G., Danabasoglu, , Dixon, K. , Giorgetta, M.A., Greene, A., Hawkins, E., Hegerl, G., Karoly, D., Keenlyside, N., Kimoto, M., Kirtman, B., Navarra, A., Pulwarty, R., Smith, D., Stammer, D., and T. Stockdale, 2009: Decadal prediction: Can it be skillful? Bull. Amer. Meteorol. Soc., pp 345-367.

Meyers, G., McIntosh, P., Pigot, L. and M. Pook, 2007: The Years of El Niño, La Niña, and Interactions with the Tropical Indian Ocean. Journal of Climate, 20, 2872-2880.

Moura, A.D., and J. Shukla, 1981: On the dynamics of droughts in northeast Brazil: observations, theory, and numerical Atmos. Sci, 38, 2653-2375.

Muhati F. D., J.M. Ininda and F. J. Opijah, 2007: Relationship between ENSO parameters and the trends and periodic fluctuations in East African rainfall, J. Kenya Meteorol. Soc., $1(1), 20-43$

Mutai, C.C, 2003: The role of Indian Ocean SST on East African Short rains. Proc. The sixth Kenya Meteor. Soc. Workshop on Meteor. Research, Applications and Services, Mombasa, Kenya, 29 September to 3 October 2003. pp 55-59.

Mutemi, J.N, 2003: Climate anomalies over eastern Africa associated with various ENSO evolution phases: Ph.D. Thesis, University of Nairobi, Kenya.

Muthama, N.J., Manene, M.M., and C.J. Ndetei, 2008: Simulation of Decadal Precipitation over Nairobi in Kenya. Journal for Science, 13 43-54.

Nicholson, S.E., and D. Entekhabi, 1986: The quasi-periodic behavior of rainfall variability in Africa and its relationship to the Southern Oscillation, Arch. Meteorol. Geophys. Bioclimatol. Ser. A, 34, 311-348.

Nicholson, S.E., and D. Entekhabi, , 1987: Rainfall variability in Equatorial and Southern Africa: Relationships with sea surface temperature along the south-western coast of Africa. J. Climate Applied Meteor., 26, 561-578.

Nicholson, S.E. and J. Kim, 1997: The relationship of the El Niño-Southern Oscillation to African rainfall. Int. J. Climatol., 17, 117-135.

Nicholson S.E., 2000a: Land surface processes and Sahel climate. Reviews of Geophysics 38: 117-139. 
Nicholson, S.E., 2000b: The nature of rainfall variability over Africa on time scales of decades to millennia. Global Planet. Change, 26, 137-158.

Njau, L.N., 2006: Diagnostics and predictability of East Africa rainfall with tropospheric circulation parameters. PhD Dissertation, Department of Meteorology University of Nairobi, 170pp.

Nobre, P., and J. Shukla, 1996: Variations of sea surface temperature, wind stress, and rainfall over the Tropical Atlantic and South America. J. Climate, 9, 2464- 2479.

Nyakwada, W., 2009: Predictability of East African Seasonal Rainfall with Sea Surface Temperature Gradient Modes: Ph.D. Dissertation, Dept. of Met: University of Nairobi.

Ogallo, L.J., 1988: Relationships between seasonal rainfall in East Africa and the Southern Oscillation. J. Climatol., 8, 31 - 43

Ogallo, L.J., 1989: The spatial and temporal patterns of the East African seasonal rainfall derived from principal component analysis. J. climat., 9, 145-167.

Okoola, R.E.A., 1996: Space-time Characteristics of the ITCZ over equatorial Eastern Africa during anomalous rainfall years. PhD Thesis Department of Meteorology, University of Nairobi, Kenya

Omondi, P.A; Ogallo L.A. and Okoola R.E, 2009: Decadal Rainfall Variability Modes in observed Rainfall Records over East Africa and their Predictability using Sea Surface Temperature, J. Kenya Meteorol. Soc., 3 37-54

Omondi P. A., Awange, J.L., Ogallo, L.A., Okoola, R.A., and E. Forootan, 2012a: Decadal rainfall variability modes in observed rainfall records over East Africa and their relations to historical sea surface temperature changes, Journal of Hydrology 464-465 (2012) 140-156.

Omondi P.A., Ogallo, L.A., Anyah, R.O., Muthama, J.M., and J. Ininda, 2012b: Linkages between global sea surface temperatures and decadal rainfall variability over Eastern Africa region International Journal of Climatology, DOI: 10.1002/joc.3578.

Owiti, O.Z., 2005: Use of the Indian Ocean Dipole indices as predictor east African rainfall anomalies. MSc Thesis, Department Of Meteorology, University of Nairobi, Kenya.

Parry M.L., Canziani, O.F., Palutikof, J.P., Van Der Linden P. J., and C.E. Hanson, 2007: Contribution of Working Group II to the Fourth Assessment Report of the Intergovernmental Panel on Climate Change, 2007. Cambridge University Press, Cambridge, United Kingdom and New York, NY, USA

Pohlmann H, Jungclaus, J. H., Köhl, A., Stammer, D., and J. Marotzke, 2009: Initializing Decadal Climate Predictions with the GECCO Oceanic Synthesis: Effects on the North Atlantic. J. Climate, in press. 
Power, S., Folland, C., Colman, A. and V. Mehta, 1999: Inter-decadal modulation of the impact of ENSO on Australia. Climate Dynamics, 15, 319-324.

Rao, S. A., and T. Yamagata, 2004: Abrupt termination of Indian Ocean dipole events in response to intraseasonal disturbances, Geophys. Res. Lett., 31, L19306, doi: 10.1029/2004GL020842.

Rao, S.A., and S.K. Behera, 2005: Subsurface influence on SST in the tropical Indian Ocean: Structure and interannual variability, Dyn. Atmos. Ocean, 39, 103-135.

Rao, S.A., Masson, S., Luo, J. J., Behera, S. K., and T. Yamagata, 2007: Termination of Indian Ocean dipole events in a general circulation model, J. Clim., 20, 3018-3035, doi:10.1175/JCLI4164.1.

Reason C.J.C, Landman, W. and W. Tennant, 2006: Seasonal to Decadal Prediction of Southern African Climate and Its Links with Variability of the Atlantic Ocean, American Meteorological Society, DOI:10.1175/BAMS-87-7-941.

Reynolds, R. W., 1988: A real-time global sea surface temperature analysis. J. Climate, 1, 75-86.

Reynolds, R. W. and D. C. Marsico, 1993: An improved real-time global sea surface temperature analysis. J. Climate, 6, 114-119.

Reynolds, R. W. and T. M. Smith, 1994: Improved global sea surface temperature analyses using optimum interpolation. J. Climate, 7, 929-948.

Reynolds, R.W., Rayne, N.A., Smith, T.M., Stokes, D.C., and W. Wang, 2002: An Improved In Situ and Satellite SST Analysis for Climate, J. Climate, 15, 1609-1625.

Richman, M.B., 1986. Review article. Rotation of principal components. J. Climat. 6, 293335.

Ropelewski, C.F., and M.S. Halpert, 1987: Global and regional scale precipitation patterns associated with the El-Nino/Southern Oscillation. Mon. Wea. Rev., 115, 1606-1626.

Saji, N.H., Goswami, B.N., Vinayachandran, P.N., and T. Yamagata, 1999: A dipole mode in the tropical Indian Ocean. Nature, 401, 360-363.

Saji, N.H., and T. Yamagata 2003a: Possible impacts of Indian Ocean dipole events on global climate, Clim. Res., 25, 151-169.

Saji, N.H., and T. Yamagata, 2003b: Interference of teleconnection patterns generated from the tropical Indian and Pacific Oceans. Climate Res., 25, 151-169.

Schreck, J. C and F.H.M. Semazzi, 2004: Variability of the recent climate of Eastern Africa. Int. J. Climatol. 24, 681-701.

Segele, T.Z. and P.J. Lamb, 2005: Characterization and variability of Kiremt rainy season over Ethiopia. Meteorology and Atmospheric Physics 89: 153-180. 
Singhrattna, N., Rajagopalan, B., Clark, M., and K.K. Kumar, 2005: Seasonal forecasting of Thailand summer monsoon rainfall, Int. J. Climatol., 25, 649-664.

Smith, T.M., and R.W. Reynolds, 2002: Bias corrections for historic sea surface temperatures based on marine air temperatures. J. Climate, 15, 73-87.

Smith, T.M., and R.W. Reynolds, 2003: Extended reconstruction of global sea surface temperatures based on COADS data (1854-1997). J. Climate, 16, 1495-1510.

Smith, T.M. and R.W. Reynolds, 2004: Improved Extended Reconstruction of SST (18541997). J. Climate, 17, 2466-2477.

Smith, D. M., Cusack, S., Colman, A.W., Folland, C.K., Harris, G.R. and J. M. Murphy, 2007: Improved surface temperature prediction for the coming decade from a global climate model. Science 317, 796-799.

Smith T. M., Reynolds R. W., Peterson T. C., Lawrimore J., 2008: Improvements to NOAA's historical merged land-ocean surface temperature analysis (1880-2006). Journal of Climate. 21: 2283-2296.

Terray, P., and S. Dominiak, 2005: Indian Ocean Sea Surface Temperature and El Nino Southern Oscillation, J Climate, 18, 1351-1368

Trenberth, K.E., and D. P. Stepaniak, 2001: Indices of El Niño evolution, J. Clim., 14, 1697 1701.

Trenberth, K. E., Caron, J. M., Stepaniak, D. P. and S. Worley, 2002: The evolution of ENSO and global atmospheric temperatures. J. Geophys. Res., 107, 4065, doi: 10.1029/2000JD000298.

Tozuka, T., Luo, J.J., Mason, S., and T. Yamagata, 2007: Decadal Modulations of the Indian Ocean Dipole in the SINTEX-F1 Coupled GCM. J. Climate, 20, 2881-2894

Tyson, P.D., and R.A. Preston-Whyte, 2000: The weather and climate of southern Africa.

Oxford University Press, southern Africa, pp 396.

Valsala, V.K. and M. Ikeda, 2007: Pathways and Effects of the Indonesian Throughflow Water in the Indian Ocean Using Particle Trajectory and Tracers in an OGCM., J Climate, 20, No.13, 2994-3017.

Venegas, S.A.,. Mysak, L.A., and D.N. Straub, 1996: Evidence for Interannual and Interdecadal Climate Variability in the South Atlantic, Geophys. Res. Lett., 23(19), 26732676.

von Storch, H. and A. Navarra, (editors), 1995: Analyses of Climate variability Applications of Statistical Techniques, Springer.

Wallace, J.M., Smith, C., and C.S. Bretherton, 1992: Singular value decomposition of wintertime sea surface temperature and 500-mb height anomalies. J. Clim., 5:561-576 
Wang, G., and E.A.B. Eltahir, 1999: Use of ENSO Information in Medium- and Long- Range Forecasting of The Nile In Floods., J. Climate, 12, 1726-1737.

Wang, C., 2002: Atlantic climate variability and its associated atmospheric circulation cells. J. Climate, 15, 1516-1536.

Ward, M.N., 1998: Diagnosis and short-lead time prediction of summer rainfall in tropical North Africa at inter-annual and multi-decadal Timescales. J. Climate, 1, 3167-3191.

Ward, M.N., and C.K. Folland, 1991: Prediction of seasonal rainfall in the north nordeste of Brazil using eigenvectors of sea surface temperature. J climatol., 11, 711-743.

Wassila, M.T., Barnston, A.G., and V. Kumar, 1999: Prediction of African rainfall on the seasonal timescale. J. Geophysics. Res., 104, D24, 31589-31597.

Weare, B.C., 1977: Empirical Orthogonal Analysis of Atlantic ocean surface temperatures, Quart. J. R. Met. Soc., 103, 467-478.

Webster, P.J., Moore, A.M., Loschnigg, J. P., and R.R. Leben, 1999: Coupled OceanAtmosphere dynamics in the Indian ocean during 1997-98., Nature, 401,356-359.

Webster, P.J., Moore, A.M. , and J. P. Loschnigg, 2005: Changes in tropical cyclone number, duration and intensity in a warming environment. Science, 309, 1844-1846.

Wilks, Daniel S., 1995. Statistical methods in the atmospheric sciences. Academic Press, New York. 467p.

Wilks, D.S, 2006: Statistical methods in atmospheric sciences, Second Edition, vol. 91. In International Geophysics Series, $2^{\text {nd }}$ edn, vol. 91. Academic Press, Elsevier: UK; 627pp. Academic press, pp 45-50, 399-402.

Wolter, K., 1987: The Southern Oscillation in Surface Circulation and Climate over the tropical Atlantic, Eastern Pacific and Indian Ocean as captured by cluster analysis. J. Appl. Meteor, 26, 540-558.

Woodhouse, C. A., and J. T. Overpeck, 1998: 2000 years of drought variability in the central United States. Bull. Amer. Meteor. Soc., 79, 2693-2714.

Worster, D., 1979: Dust Bowl: The Southern Great Plains in the 1930s. Oxford University Press, New York, 277pp.

Wu, L., He, F., Liu, Z., and C. Li, 2007: Atmospheric teleconnections of tropical Atlantic variability: Interhemispheric, tropical-extratropical, and cross-basin interactions. J. Climate, 20, No.5, 856-870.

Xoplaki, E., Gonzalez-Rouco, J., Gyalistras, D., Luterbacher, J., Rickli, R., and H. Wanner, 2003: Interannual summer air temperature variability over Greece and its connection 
Page 47 of $\mathbf{4 7}$

to the large-scale atmospheric circulation and Mediterranean SSTs 1950-1999. Clim. Dyn. 20, 537-554.

Xie, S.-P., Annamalai, H., Schott, F.A., and J. P. McCreary Jr, 2002: Structure and mechanisms of South Indian Ocean climate variability. J. Climate, 15, 864-878.

Xinhua C., and J. D. Timothy, 1995: Orthogonal Rotation of Spatial Patterns Derived from Singular Value Decomposition Analysis, Journal of Climate, 8, 2631-2643.

Yu, L., and M.M. Rienecker, 2000: Indian Ocean warming of 1997-98., J. Geophys. Res., 105, 16 923-16939.

Zhang, R., and T.L. Delworth, 2006: Impact of Atlantic multidecadal oscillations on India/Sahel rainfall and Atlantic hurricanes. Geophys. Res. Lett., 33, L17712, doi: 10.1029/2006GL026267.

Zewdu T.S., Lamb, P.J. and L.M. Leslie, 2009: Large-scale atmospheric circulation and global sea surface temperature associations with Horn of Africa June - September rainfall, Int. J. Climatol., 29: 1075-1100. 